\title{
Formes vocales et instrumentales de la tradition musicale savante issue de la Renaissance de l'Orient arabe
}

\section{Nidaa Abou Mrad}

\section{(2) OpenEdition \\ Journals}

Édition électronique

URL : http://journals.openedition.org/ethnomusicologie/464

ISSN : 2235-7688

Éditeur

ADEM - Ateliers d'ethnomusicologie

Édition imprimée

Date de publication : 1 janvier 2004

Pagination : 183-215

ISBN : 2-8257-0910-7

ISSN : $1662-372 X$

\section{Référence électronique}

Nidaa Abou Mrad, « Formes vocales et instrumentales de la tradition musicale savante issue de la Renaissance de l'Orient arabe ", Cahiers d'ethnomusicologie [En ligne], 17 | 2004, mis en ligne le 13 janvier 2012, consulté le 19 avril 2019. URL : http://journals.openedition.org/ethnomusicologie/464

Ce document a été généré automatiquement le 19 avril 2019

Tous droits réservés 


\title{
Formes vocales et instrumentales de la tradition musicale savante issue de la Renaissance de l'Orient arabe
}

\author{
Nidaa Abou Mrad
}

1 L'application de la notion de forme musicale au contexte de la tradition musicale savante de l'Orient arabe pose problème. Certains types de séquences vocales et instrumentales répondent, certes, à des schémas structurels clairs et nets, faisant se succéder les segments mélodiques constitutifs selon un ordre préétabli qui est minutieusement décrit dans les traités autochtones. Il s'agit, en fait, de séquences mesurées, à cycles rythmiques, totalement précomposées, ce qui revient à dire que leur phrasé, dans sa fixité, est issu intégralement $\mathrm{du}$ répertoire traditionnel, ou bien qu'il est établi par un compositeur avant la performance ${ }^{1}$. La marge de transformation allouée au performeur est alors restreinte à une ornementation improvisée du phrasé, laquelle ne rallonge pas le débit de reproduction de ladite composition: aucune mesure n'est rajoutée ou retranchée au parcours rythmique et mélodique originel. Le degré de lisibilité - au premier degré - des formes de ces séquences est, de ce fait, proportionnel à celui du statisme de la performance, c'est-à-dire à celui de l'inféodation de cette dernière (réalisation) à la littéralité de l'œuvre (modèle).

2 En revanche, un grand nombre de séquences échappe à ce genre d'analyse fixiste. Leur phrasé est, en effet, partiellement ou totalement élaboré au moment de la performance musicale par un musicien (ou un ensemble de solistes) qui cumule en conséquence les fonctions de compositeur et de performeur. Aussi la prééminence des dynamiques improvisatives dans la constitution du phrasé de ces séquences impose-t-elle une fluctuation continue à leurs «formes». A partir de ce point, les analyses peuvent suivre deux voies distinctes:

- Se concentrer sur les formes musicales fixes ou fermées et négliger celles qui sont sujettes à des fluctuations structurelles en rapport avec l'improvisation, comme le suggère avec philosophie Hasan al-Kātib (théoricien arabe du Xe siècle): « En ce qui concerne les improvisations du musicien, c'est un domaine qui nous échappe» (Shiloah 1972: 138). C'est, 
du reste, l'attitude qui prédomine chez les pionniers de la musicologie orientaliste et les théoriciens et pédagogues arabes du XXe siècle, en quête de formes et de répertoires à contours fixes (Lagrange 1996: 89).

- Analyser les séquences fluctuantes pour en saisir les rouages et établir des modèles descriptifs dynamiques qui tentent d'introduire de la lisibilité là où une certaine confusion semble régner sous couvert d'improvisation fourre-tout.

La seconde voie sera empruntée dans le propos qui suit, lequel constitue une tentative de repérage des structures formelles et des processus créatifs les animant au sein de la tradition musicale savante du Proche-Orient arabe, dans sa mouture réactualisée au XIX ${ }^{\mathrm{e}}$ siècle.

\section{La Renaissance musicale de l'Orient arabe}

3 Née au cours de "l'Âge d'Or» de la dynastie Abbasside, la grande tradition musicale arabo-persane, devenue arabo-persano-turque à partir du XIV ${ }^{\mathrm{e}}$ siècle, faisait jusqu'au $\mathrm{XVII}^{\mathrm{e}}$ siècle office de référence normative dans l'ensemble de l'Orient musulman (During 1994: 107). Ce tronc s'est lézardé sous les assauts conjugués des particularismes régionaux qui ont poussé les trois composantes de cette tradition artistique à suivre des voies différentes, tant du point de vue des échelles modales, que des formes et de l'instrumentation, sans pour autant diverger dans leur essence. Aussi cette sphère culturelle ne connaissait-elle plus au début du XIX ${ }^{\mathrm{e}}$ siècle que deux traditions artistiques et savantes dignes de ce nom, à Istanbul et à Alep, celle-ci se trouvant assujettie, par divers aspects, à celle-là ${ }^{2}$. Partout ailleurs, des traditions musicales citadines déliquescentes, pâles réminiscences d'une musique d'art délaissée, faute de mécénat et de climats propices.

4 La seconde moitié du XIX ${ }^{\mathrm{e}}$ siècle a connu une conjoncture sociopolitique favorable qui a donné un second souffle à l'Orient arabe et plus particulièrement à l'Égypte, du moins pour un bref moment à l'échelle de l'Histoire. La Renaissance arabe ou Nahda ${ }^{3}$ est marquée par un climat d'effervescence culturelle au centre de laquelle on trouve des relents "d'Âge d'Or», aux côtés de questionnements identitaires et religieux, ainsi que d'irrésistibles aspirations à la modernité. Elle s'est traduite par des dynamiques de réforme et de renouvellement tous azimuts, notamment en religion, pensée politique, lettres et musique, qui ont emprunté des voies pour la plupart endogènes au XIX ${ }^{\mathrm{e}}$ siècle (Hourani 1962-1977). Les attitudes prônant des syncrétismes exogènes (occidentalismes) attendront l'achèvement de la Première Guerre mondiale pour prendre leur essor, en même temps que la réaction «salafiste ${ }^{4}$ » dans ses différentes déclinaisons intégristes et fondamentalistes (Sayed 2003: 33-48).

5 Le prologue de la renaissance musicale arabe se déroule dans les cercles musicaux levantins. Le théoricien libanais Mīhā̄îl Maššāqah (1800-1888), disciple du musicien damascène Cheikh Mụammad al-'Ațtāar, en représente à la fois le fer de lance et le témoin qui réalise sa première mise en théorie (Maššāqah 1899).

6 La contagion gagne rapidement la vallée du Nil, qui connaît, au cours du dernier tiers du $\mathrm{XIX}^{\mathrm{e}}$ siècle et à l'instigation du khédive Ismā‘îl Pacha (1863-1879), vice-roi d'Egypte, un courant de renouveau musical dominé par la figure du chanteur et compositeur 'Abduh al-Ḥāmūlī (1843-1901). Cette école ${ }^{5}$ a élaboré une nouvelle musique de cour ${ }^{6}$ à partir de la tradition musicale populaire citadine égyptienne, en l'enrichissant d'éléments provenant des musiques savantes ottomane et alépine, introduites depuis plus d'un siècle en Egypte, 
et des traditions musicales religieuses et parareligieuses soufies locales et régionales (Abou Mrad 1991 : 141-150 et 2003: 49-70 et Lagrange 1996, ch. III).

7 Aussi cette réforme a-t-elle permis l'éclosion d'une nouvelle tradition musicale artistique égyptienne et, plus généralement, arabe proche-orientale, sorte d'avatar moderne de la tradition médiévale de l'Orient arabo-musulman, aux côtés de la tradition musicale savante iranienne du radîf, axée sur les modes dastgāh, apparue à la fin du XIX ${ }^{e}$ siècle (During 1994: 108 et 220-229), tout comme la renaissance des traditions du maqām iraqien (Hassan 1987: 143-149 et 2003: 99-116) et du mugām azéri.

Fig. 1 : 'Abduh al-Ḥāmūlī (1843-1901)

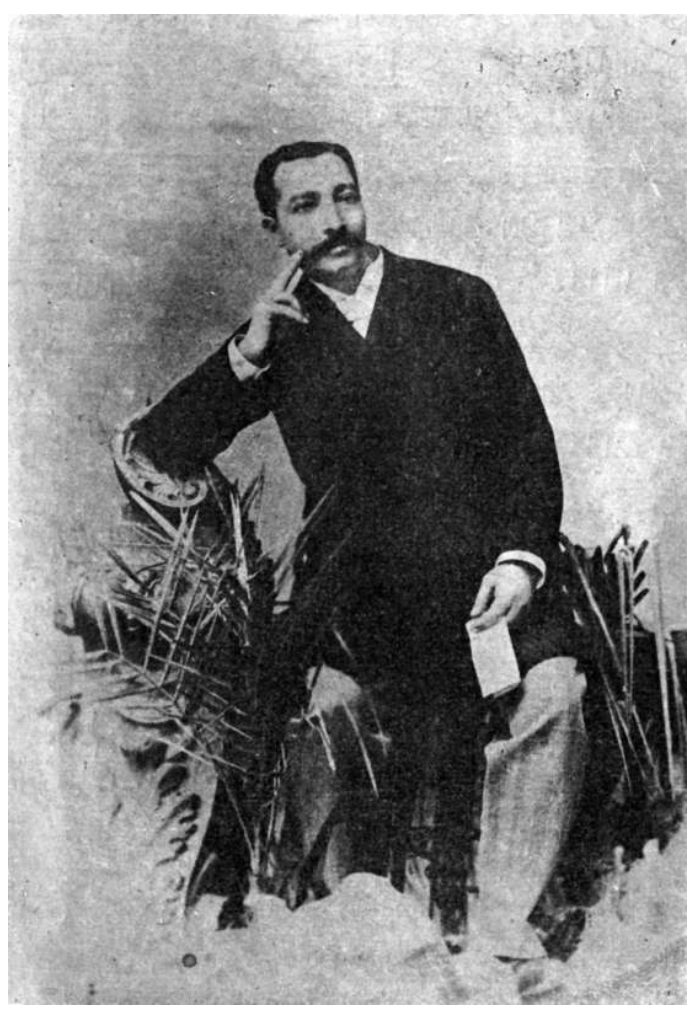

De fait, il s'agit d'une musique savante, car elle repose sur un langage riche et complexe, doté d'une théorie écrite ${ }^{7}$, et fait intervenir à chaque moment des schémas de renouvellement créatif. La richesse de cette tradition réside dans les échelles et les structures modales héritées du système médiéval, dans lesquelles s'insèrent des nuances d'intervalles et des idiosyncrasies mélodiques porteuses de spécificités culturelles, d'une part, et, d'autre part, dans les équations complexes de l'articulation mélodique et rythmique. La créativité instantanée s'exprime à chaque moment de la performance musicale qui se trouve organisée sous forme de wașla, ou succession de séquences instrumentales et vocales se déroulant au sein d'un même mode maqām, et assumée par le taht ou ensemble de solistes chanteurs et instrumentistes.

\section{Dialectique de la cantillation et de la ritournelle}

9 L'analyse du processus de constitution (ou de reconstitution) d'une tradition artistique, comme celle du Proche-Orient arabe, à partir de traditions populaires locales, en interaction avec des traditions musicales savantes régionales préexistantes, fortement 
imprégnées de religion, ou du moins de spiritualité, invite à cerner les affiliations culturelles des éléments musicaux engagés dans ce remue-ménage.

Sans adopter la démarche de Gilles Deleuze et Félix Guattari (1980), la ritournelle apparaît comme une séquence musicale compacte, à fort enracinement territorial ${ }^{8}$. Par exemple: un motif mélodique mesuré, fixe et récurrent, un «modèle dense», "monomodulaire figé» (Lortat-Jacob 1987: 49-59) ou à variations restreintes, facile à retenir, repérable quant à son origine culturelle (souvent populaire et profane) et se prêtant volontiers à une performance collective.

11 Dans un autre registre, la cantillation, lecture mélodieuse soumise à la métrique prosodique d'un texte et à une structure mélodique modale, permettant l'improvisation, tout en restant assujettie à l'exemplarité d'un corpus mélodique traditionnel, réfère à un modèle musical moins densifié ${ }^{9}$ que celui de la ritournelle.

12 L'opposition cantillation/ritournelle recouvre, de fait, la polarisation entre parole et geste, de même que la dialectique non mesuré/mesuré qui régente toute rythmique. Cette dichotomie s'exprime dans les traités arabes médiévaux sur la musique par l'emploi de métaphores littéraires qui permettent de marquer la différence entre mélodie mesurée et mélodie non mesurée. Ainsi Al-Kātib (Shiloah 1972: 143) oppose-t-il, à la fin du X $\mathrm{X}^{\mathrm{e}}$ siècle, laḥn mursal wa-mutawāṣil, non mesuré (dépourvu de pulsations isochrones) et continu, à laḥn muharrar wa-muqațta', mesuré avec netteté (grâce à des pulsations isochrones lentes), le mursal étant de la prose, du point de vue littéraire (selon Al-Baqillānī, cité par Shiloah, ibid.). De même et au XVe siècle, le Traité anonyme dédié au Sultan Osmānlī Mụammad II (Erlanger 1939: 233) opère une nette distinction entre naz̧m a-n-naġamāt (élaboration mesurée de la mélodie), lorsqu'il s'agit de «chanter des vers sur des notes mesurées ( nağamāt muwaqqa'a)», et natr a-n-naġamāt (élaboration non mesurée de la mélodie), quand il faut « chanter des vers sur des notes libres (naġamāt.hurra)», et ce, en étendant au plan musical la dialectique littéraire entre nażm - versification poétique (paroles mesurées) et natr - prose (paroles libres).

\section{Musicalisation du verbe: la cantillation}

13 Selon la typologie rythmique de Jacques Chailley (1996: 17), le rythme verbal, non forcément isochrone, se voit privilégié dans la musique vocale, où il s'associe volontiers à la déclamation des paroles. "Le rythme verbal est moins fréquent dans la musique instrumentale, encore qu'il y ait souvent décalque de l'un sur l'autre».

14 La cantillation désigne une musicalisation traditionnelle de la récitation d'un texte. Il s'agit à la base de la mélodisation d'une prose sacrée, dans le cadre des religions monothéistes (judaïsme, christianisme, islam), mettant en avant la parole révélée, ancrage de la prière, de la prédication et de l'enseignement, ainsi que de la dévotion tant personnelle que collective (Shiloah 2003: 316-317). Rejetant le caractère mondain du ton de l'orateur - qu'il fût politicien ou philosophe - le lecteur enseignant a toujours eu tendance à «mélodiser» sa lecture, permettant ainsi de protéger l'énoncé du Logos divin par une stylisation traditionnelle des intervalles de la voix (Corbin 1960-2000: 61-62) ${ }^{10}$.

L'amplification du texte scripturaire se traduit, sur le plan métrique, par la mise en valeur du débit microrythmique des syllabes successives du texte et, sur le plan mélodique, par une articulation du phrasé, laquelle est centrée sur les cordes de récitation et entrecoupée de formules mélodiques qui marquent l'intonation et la ponctuation 
(disjonctive, conclusive, etc.) et soulignent ainsi la structure modale (Chailley, ibid.: 110 et Corbin, ibid.: 62).

16 En appliquant les critères d'analyse de Bernard Lortat-Jacob (1987: 45-59), la cantillation procède d'une musique improvisée non mesurée, plurimodulaire (mettant en jeu des unités inféodées au débit microrythmique de la prose, d'ordre et de dimension fort variés, se regroupant dans des espaces irréductibles les uns aux autres), dans laquelle les modes (partie intégrante du modèle) sont figurés progressivement, par paliers.

La forme arabe du taqsìm (littéralement: morcellement) peut être assimilée à une sorte de «cantillation instrumentale» d'une prose virtuelle, implicite, imprononcée. La musique ottomane emploie le même terme taksim ${ }^{11}$ pour désigner l'improvisation vocale et l'improvisation instrumentale. Cette forme est envisagée par Jean During (1987: 34) comme un ensemble morcelé et impromptu de séquences, voire de modules modaux enchaînés les uns aux autres. L'ordre de succession de ces mêmes modules, représentant une sorte de projection ou d'effectuation temporelle de l'architecture du mode exploré, réalise ce que Bernard Lortat-Jacob (ibid.: 54-56) - dans la foulée de Riccardo Canzio décrivant l'ālāp indien (1982, cité par Lortat-Jacob ibid.) - désigne par " parcours obligé»: la durée des éléments échappe au modèle, mais non leur importance respective. Aussi le modèle intervient-il dans leur ordre d'apparition, qui est régulé par des seuils de gradation et de rupture. prosodique, sa dimension mélodique est assujettie à des normes plus complexes. Il ne suffit pas, en effet, de faire référence à la structure d'un mode mélodique donné, pour que surgisse, comme par magie, le phrasé idoine. Dans certaines formes primaires de cantillation, la modalité peut, certes, se résumer - outre la définition de l'échelle, des degrés pivots et autres registres de récitation, et outre l'expression d'un éthos ('ațar ou a $a l)^{12}$ déterminé - à un certain nombre de formules d'intonation, de ponctuation et de conclusion. Il s'agit de la notion de « mode formulaire» chère à Tran Van Khé(1971). Dans les formes élaborées de cantillation, en revanche, l'élaboration instantanée du phrasé se fait en référence à un modèle constitué d'un grand nombre d'exemples mélodiques, propres à leurs modes respectifs. Il s'agit d'un "répertoire modèle», expression par laquelle Jean During (1991) désigne en particulier le radif iranien, corpus traditionnel de référence qui repose sur des phrases exemplaires, non mesurées et cantillatoires: les gushe. De même, la tradition musicale savante du Proche-Orient arabe englobe des répertoires modèles propres aux formes existantes. Les recueils édités au XIX ${ }^{\mathrm{e}}$ siècle $^{13} \mathrm{en}$ ont perpétué les textes, regroupés par modes et formes. Les enregistrements gravés sur 78 tours, avant la Grande Guerre, en ont immortalisé la musique. Au-delà du rôle de référence normative («modèle inerte»), ce répertoire modèle « joue le rôle d'une matrice et prend dans ces circonstances une fonction génératrice» (Lortat-Jacob 1987: 51).

Quant à l'expression en langue arabe de la notion de cantillation, dans un contexte islamique aussi bien que chrétien arabophone, elle se trouve être plurale, parfois ambivalente. Ainsi, le terme tajwid, qui signifie perfectionnement, prend dans un contexte religieux le sens de "parure de la récitation (qirā’a ou tilāwa)» des versets du Coran. Partant, sa réalisation prend deux sens différents et complémentaires: perfectionnement de l'élocution et perfectionnement de la musicalisation de la récitation. Il y a lieu de distinguer trois niveaux de récitation:

- 1. Le tajwìd-taqiqa: stricte observance des règles canoniques de la langue arabe quant à la grammaire, la phonétique et la prosodie, celle-ci imposant une juste répartition des durées 
relatives sur les syllabes successives, ainsi que le respect de la ponctuation, pauses ou arrêts (Shiloah 1991: 92).

- 2. Le tarti ${ }^{14}$ simple: style de cantillation syllabique qui attribue à chaque syllabe un seul son mélodique, sur une tessiture modale exiguë, et qui n'admet que très rarement une ornementation, du reste, fort compacte.

- 3. Le tajwìd-qirā'a bi-l-'aḷān: style de cantillation ornée et mélismatique qui s'inscrit dans les schémas mélodiques de la musique savante de l'Orient arabe ${ }^{15}$.

Au total, pour arabiser "cantillation» dans un sens générique ou général, il convient d'employer une expression de type "récitation chantée», comme « tilāwa murannama» ${ }^{16}$.

Les procédés de lecture chantée sont appliqués également à la poésie arabe classique, qu'elle fût mystique ou profane, de même qu'à la poésie dialectale. Plus encore, inšăd signifie, depuis l'époque préislamique et jusqu'au $\mathrm{X}^{\mathrm{e}}$ siècle, à la fois déclamation d'un poème classique (qașida) et récitation chantée ou cantillation (restreinte d'un point de vue musical) du poème. Or, la poésie suppose l'instauration d'une métrique prosodique, donc d'une forme de périodicité du débit rythmique inhérente aux paradigmes de la versification arabe. Cependant, l'intrusion d'une périodicité microrythmique verbale n'entraîne pas forcément l'établissement d'une périodicité rythmique globale ou macrorythmique: mesure ou cycle rythmique. La cantillation poétique reste alors non mesurée ou à rythme anisochrone. C'est du reste, semble-t-il, la tendance dominante dans les pratiques musicales préislamiques, en dehors du idā' (et de son dérivé, an-nașb) ou chant des caravaniers qui correspond à une convergence entre le rythme gestuel des chameaux et le rythme verbal du paradigme métrique du idàa', c'est-à-dire le rajaz ( «mustafilun») premier mètre prosodique dont les poètes arabes se seraient servis (Erlanger 1959: 158).

22 Avec l'avènement de la musique artistique à Damas, pour les Omeyyades, puis à Bagdad, pour les Abbassides, une nouvelle forme musicale s'est constituée à partir du mariage entre la qașida et les cycles rythmiques arabes néoformés (probablement sous influence Sassanide). Il s'agit du șawt, qui dominera jusqu'au XIII siècle toute la production musicale de l'Orient arabe. Cette forme est constituée de deux parties, selon le chroniqueur du Xe siècle Abū Al-Faraj Al-Iṣfahānī (1927-1974, V: 427), successivement: le našĭ ${ }^{17}$, cantillation probablement non mesurée et le basiț qui emploie une mélodie mesurée et rigoureusement calquée sur le texte, sans addition de mots ni de musique (Erlanger, 1939: 244) qui est reprise à l'identique à l'énoncé de chaque vers du șawt (Poché, 1995: 41-42). Quelques décades plus tard, Al-Kātib (Shiloah 1972: 129) en se référant à Al-Kindi (IXe siècle) affirme que «le našìd consiste à chanter au début d'un poème, ou au début d'un discours qui n'est pas en vers, quelques mots dont la mesure ne sera pas marquée et que le istihläl consiste à exécuter, au début d'un chant, un seul mot dans un rythme libre.» Il précise ensuite que le našíd peut se dérouler sur plusieurs vers. Ainsi, ces formes introductives du șawt, toutes deux cantillatoires non mesurées, se distinguent par le fait que le našìd consiste en un récitatif rigoureux d'un ou de deux vers, tandis que l'istihlāl, se saisissant d'un seul mot, est sujet à une inventivité débridée, préfigurant le taqsìm-Yā leyl de la Nahḍa.

23 Tel est également le cas du taġazzul, ou de la première partie (šațr) de našĩd al-'Arab, formes décrites au XVe siècle dans le Traité anonyme dédié au Sultan Osmānlī Mụammad II (Erlanger 1939: 233), en tant que séquences répondant aux attributs de natr a-n-naġamāt, élaboration non mesurée de la mélodie (naġamāturra). 
Quant à la cantillation instrumentale, elle ne représente pas un type intermédiaire entre
cantillation et ritournelle, mais entre cantillation et musique instrumentale. Il s'agit de la
forme improvisative du taqsim précédemment décrite. Le phrasé instrumental de cette
forme, en l'absence de toute parole explicite chantée, reflète par son débit
microrythmique les idiosyncrasies métriques de la langue arabe, méritant totalement la
dénomination de cantillation instrumentale.

Quant à la cantillation instrumentale, elle ne représente pas un type intermédiaire entre
cantillation et ritournelle, mais entre cantillation et musique instrumentale. Il s'agit de la
forme improvisative du taqsim précédemment décrite. Le phrasé instrumental de cette
forme, en l'absence de toute parole explicite chantée, reflète par son débit
microrythmique les idiosyncrasies métriques de la langue arabe, méritant totalement la
dénomination de cantillation instrumentale.

Quant à la cantillation instrumentale, elle ne représente pas un type intermédiaire entre
cantillation et ritournelle, mais entre cantillation et musique instrumentale. Il s'agit de la
forme improvisative du taqsim précédemment décrite. Le phrasé instrumental de cette
forme, en l'absence de toute parole explicite chantée, reflète par son débit
microrythmique les idiosyncrasies métriques de la langue arabe, méritant totalement la
dénomination de cantillation instrumentale.

Quant à la cantillation instrumentale, elle ne représente pas un type intermédiaire entre
cantillation et ritournelle, mais entre cantillation et musique instrumentale. Il s'agit de la
forme improvisative du taqsim précédemment décrite. Le phrasé instrumental de cette
forme, en l'absence de toute parole explicite chantée, reflète par son débit
microrythmique les idiosyncrasies métriques de la langue arabe, méritant totalement la
dénomination de cantillation instrumentale.

Quant à la cantillation instrumentale, elle ne représente pas un type intermédiaire entre
cantillation et ritournelle, mais entre cantillation et musique instrumentale. Il s'agit de la
forme improvisative du taqsìm précédemment décrite. Le phrasé instrumental de cette
forme, en l'absence de toute parole explicite chantée, reflète par son débit
microrythmique les idiosyncrasies métriques de la langue arabe, méritant totalement la
dénomination de cantillation instrumentale.

Il en est de même pour la qasìda aala lanin mursal, forme de poésie arabe classique cantillée pratiquée aux XVIII ${ }^{e}$ et $\mathrm{XIX}^{\mathrm{e}}$ siècles notamment par les milieux soufis des grandes villes du Proche-Orient. Cette cantillation impromptue peut être accompagnée par des instruments qui préludent par l'improvisation de taqāsim et reproduisent en écho l'énoncé vocal sous forme de murāsala et tarjama.

Ces procédés sont également à l'œuvre dans le traitement du mawwāl, forme de poésie dialectale cantillée répandue dans l'ensemble du Proche-Orient, ayant donné naissance, au cours du dernier tiers du XIX siècle, à une forme de chant artistique égyptien improvisé (Lagrange 1994: ch. V).

\section{Musicalisation du geste: la ritournelle instrumentale}

Selon la vision rythmique développée par Jacques Chailley, le rythme gestuel, stylisation des gestes réguliers de la marche, de la danse, etc., se démarque du rythme verbal, stylisation du rythme de la parole dans l'idiome employé. « Le rythme gestuel isochrone, privilégié au départ dans la musique instrumentale, a souvent contaminé la musique vocale. [...] Son exaspération souvent répétitive [est] fréquente dans les musiques à vocation magique» (Chailley 1996: 17-18).

La ritournelle instrumentale, tarğì, lāzima ou tašyi ${ }^{i} a$, apparaît comme un (sinon le) prototype de mélodisation du geste et de précomposition musicale. Par la périodicité de la pulsation isochrone, ou des battues cycliques macrorythmiques, la ritournelle colle aux pas du geste (danse, marche). Par la périodicité de ses occurrences mélodiques dans le cycle rythmique, la ritournelle s'homologue aux figures de ce même geste. Elle constitue le degré zéro du « modèle monomodulaire figé».

\section{Musicalisation de la parole et du geste: types intermédiaires}

En dehors de la cantillation non mesurée stricte, la musicalisation de la poésie peut s'appuyer sur un macrorythme périodique, représenté, au minimum, par la mesure binaire simple de la wahda et, au maximum, par un cycle rythmique complexe. Lorsque la mesure au sein de laquelle se déploie le rythme verbal demeure discrète et ne perturbe que très modérément le débit microrythmique, tout en n'imposant pas de récurrence mélodique modulaire, la musicalisation des vers prend l'aspect d'une cantillation mesurée. La périodicité est concrétisée dans ce cas par l'usage minimaliste de la mesure binaire de la wahda. En revanche, lorsque le rythme gestuel prend le pas sur le rythme verbal, et qu'une «modularité figée» se met en place par le biais de la cristallisation de plages musicales strophiques respectant à peine la métrique poétique, il ne s'agit plus d'une cantillation mesurée de la poésie, mais d'une musicalisation fixiste et répétitive de cette dernière selon les normes hymniques: al-inšăd (du verbe anšada), selon son acception moderne. 
31 Rappelons que l'hymne de l'antiquité grecque est une composition poétique à caractère strophique, chantée sur une seule mélodie et accompagnée souvent de gestes et de déplacements (Encyclopédie de la musique, 1983-1993-1995: 366). Le psaume joue un rôle équivalent dans le contexte hébraïque en sorte qu'une tradition ecclésiale ancienne, selon Solange Corbin (ibid: 127), aurait mis dans le même sac «hymnes, psaumes et cantiques» pour signifier " louange chantée et adressée à Dieu». Dès le IV ${ }^{e}$ siècle l'Eglise syrienne a développé avec Saint Ephrem un riche répertoire hymnique en réaction aux corpus semblables mis en vogue par les cercles hérétiques.

32 Dans le contexte arabe, une mutation s'opère au $\mathrm{XV}^{\mathrm{e}}$ siècle quant au concept de l'inšăd, avec l'apparition de našìd al-'arab (hymne des Arabes), forme bipartite dans laquelle les deux ou quatre premiers vers (bayt, pl. abyāt) sont cantillés selon un rythme anisochrone ( națr a-n-naġamāt), tandis que les deux suivants sont chantés sur une seule et même mélodie mesurée (națm a-n-naġamāt) assise sur un cycle rythmique (Erlanger 1939: 233-235).

De fait, našĩd al-'arab prend la place de l'ancien șawt. La seconde partie du našĩd nouvelle manière s'apparente au basiṭ (qui continue à être chanté en langue arabe), ainsi qu'au qawl (forme médiévale arabe tardive, dérivée du șawt) et à la forme persane homothétique, le gazel. Ces quatre formes admettent souvent (depuis le XIV ${ }^{\mathrm{e}}$ siècle ${ }^{18}$ ) une séquence intercalaire médiane mélismatique: șawt al-wasaț ou miyat hāāna (mélodie médiane, qui deviendra la hāana du muwašša et la miyān du beste au XVII ${ }^{\mathrm{e}}$ siècle), transformant la section mesurée à deux vers et mélodie unique AA en une forme récurrente $\mathrm{AABA}$. La partie $\mathrm{B}$ est souvent prolongée par une séquence d'onomatopées, désignée par tarannum, sorte de trope d'interpolation dépourvu de sens verbal et remplaçant un long mélisme.

34 A partir du XVII e siècle, l'inšād prend la forme du muwašša à Alep et du beste à Istanbul. Le muwašša d'un point de vue littéraire est une forme de poésie arabe plurimètre et pluririme, apparue au $\mathrm{X}^{\mathrm{e}}$ siècle en Andalousie. Cette forme poétique s'est ensuite répandue dans les contrées du Mašreq. Aussi les cercles musicaux d'Alep s'en sont-ils emparés et lui ont-ils appliqué le schéma AABA de musicalisation du qawl et du basiț. En règle générale seuls quatre vers étaient retenus d'un muwǎšsạ littéraire - ou, souvent, d'une qașida traitée ici en muwašša musical - pour devenir les sections suivantes: dawr 1, dawr 2, hāana, qafla (AABA).

Les musiciens d'Istanbul ont fait de même en appliquant le schéma musical du gazel persan et du basit arabe à la poésie en quatrains turcs de type gazel (poésie amoureuse) désignée par murabba et ce, selon le schéma suivant: zemin, zemin, miyān, zemin, la séquence pouvant être prolongée par un terennum (Feldman s.d.: 18-19). Ainsi sont nés le muwašs̆a chanté alépin et le beste ottoman, dont la forme musicale obéit au schéma AABA, A étant la mélodie principale des vers (bayt, dawr, zemin) et B étant celle de la mélodie médiane (miyān, h̆āna).

Quant aux milieux confrériques soufis du Proche-Orient, ils ont adapté à la forme du muwašša chanté des textes religieux de louange du Prophète (madị nabawī), plus rarement des textes mystiques et ce, probablement, depuis le XVII ${ }^{e}$ siècle. Cela a donné naissance à la catégorie musicale hymnique islamique de l'inšăd (muwaqqa') dīnī ou du tawṣ̌̆ din̄i.

Si la cantillation est œuvre de soliste et la ritournelle l'affaire d'un ensemble instrumental ou vocal, les musiques strophiques à caractère hymnique, comme l'inšăd muwaqqa', 
admettent les deux types de performance, voire privilégient l'alternance solo-tutti. Le responsorial est précisément un moyen de régenter cette alternance.

La forme basique ou primitive du responsorial consiste en la reprise en chœur et en homophonie, en respectant sa longueur ou en le raccourcissant, l'énoncé du soliste (Poché 1995: 150). S'agissant d'un énoncé en solo de type cantillatoire non mesuré, la réponse du chœur, tout en respectant l'aspect cantillatoire originaire, se simplifie et se densifie pour devenir un fragment mixte cantillatoire et monomodulaire. Al-Kātib (Shiloah 1972: 124) décrit à cet égard le tarğì (recyclage) qui consiste en un module formé de notes longues empruntées à la mélodie sur laquelle est chanté le vers et qui sont reprises sous forme de ritournelle.

Cette influence «densifiante» du responsorial s'exerce également sur l'énoncé du soliste qui est généralement de type poétique versifié, comme dans les Psaumes et l'inšăd. Il s'agit alors d'une forme de psalmodie responsoriale faisant alterner les énoncés cantillatoires mesurés du soliste (célébrant ou autre) avec les réponses simplifiées du chœur.

Dans la forme élaborée du responsorial, représentée par le responsorium ou répons liturgique chrétien, c'est une ritournelle chorale autonome, l'antienne (latine) ou l'antiphona (byzantine), qui répond aux versets entonnés par le célébrant.

On retrouve ce genre de traitement notamment dans les pratiques musicales islamiques hymniques de l'inšăd et du tawṣ̌̆ (voir supra), lorsqu'une ritournelle vocale, tarğĭ ou lāzima, s'insère dans le cours du chant strophique. En conséquence de cette inférence, une sorte de féconde irrégularité s'installe dans le déroulement du phrasé du soliste qui se met à improviser et à interpoler des modules musicaux inédits, habillés des strophes préexistantes et ce, en porte-à-faux quant à la régularité de l'énoncé des ritournelles. Les effets de tuilage vocal hétérophonique entre les «tirades» cantillatoires mélismatiques (modérément) mesurées, improvisées par le chantre (munšid) et les réponses du petit chœur de la bițāna (qui rassemble un petit effectif de chantres chargés d'énoncer les versions conventionnelles des modules vocaux) sont caractéristiques de l'inšăd de haute volée.

Moins animé est le type de psalmodie responsoriale pratiqué dans les traditions musicales populaires de la région, notamment la 'Atāba-Mījanā, et le zajal libanais ${ }^{19}$, formes cantillatoires poétiques populaires à ritournelles, ou dans le šallāl yéménite (Poché 1995: 150). Dans d'autres cas, la ritournelle vocale et chorale est totalement homogène aux énoncés du soliste, auquel cas il s'agit d'une forme vocale à refrain-couplet, dans laquelle alternent deux modules musicaux (parfois identiques), revêtus d'un texte constant pour le module-refrain et d'un texte variable pour le module-couplet.

Les traditions musicales populaires du Proche-Orient arabe font grand cas de cette forme de chanson bimodulaire, communément désignée par 'uhzūja, le refrain étant nommé radda ou maḍhab. Ce dernier vocable désigne notamment la première partie de la taqtūqah populaire citadine, connue dès le XIX ${ }^{e}$ siècle en Egypte, et de son équivalent alépin le qadd . Il s'agit d'une chanson en poésie dialectale, s'appuyant sur un cycle rythmique binaire et répondant à une structure formelle bimodulaire répétitive, faisant alterner - du point de vue verbal - refrain maḍhab et couplets ag̣șān (sing. guușn).

Par ailleurs, des modules instrumentaux peuvent s'insérer dans le déroulement d'une composition vocale strophique. Deux types se distinguent à cet égard: le court prélude intégré à la composition vocale et les modules intercalaires. En matière de préludes, il 
s'agit d'abord de la țariqa (pl. tarāiq, signifiant "voie», "manière») médiévale, court prélude instrumental apparu en musique savante arabe entre le $\mathrm{IX}^{\mathrm{e}}$ et le $\mathrm{X}^{\mathrm{e}}$ siècles, probablement en imitation des rawāsin ou préludes persans (Shiloah 1972: 197). Cette séquence avait pour rôle d'esquisser rapidement l'architecture modale laquelle était elle aussi désignée par țariqa jusqu'au XIII ${ }^{\mathrm{e}}$ siècle. Cette forme est intégrée à la fin du Moyen Age à chacune des formes vocales majeures arabes et persanes, c'est-à-dire le basiṭ isolé et les quatre formes de la nawbah: qawl, ġazal, tarānah, frudāšt, tandis que les praticiens commencent à la désigner par pišru (Erlanger 1939: 230). Elle donne probablement naissance au pešrev ottoman au XVI ${ }^{\mathrm{e}}$ siècle.

Le dūläb, court prélude instrumental, ébauchant et amorçant le mode, employé dans la musique savante de la Nahḍa du Proche-Orient arabe, représente, en quelque sorte, un succédané tardif de la țariqa médiévale. Cette forme est à la base bipartite, avec une section introductive répétable et une autre conclusive (SISC ou SISISC). Une section médiane répétable peut s'intégrer à l'édifice qui devient tripartite (SISMSC ou SISISMSMSC).

Quant à la première mention nominative d'une ritournelle instrumentale intégrée à un chant, elle est le fait d'Al-Kātib au X siècle (Shiloah ibid:125). Il s'agit de la tašyi'a (accompagnement) qui est un module généralement instrumental (mais qui peut être chanté), énoncé après la fin de la mélodie d'un vers, à l'instar de la harğa, ritournelle et postlude de la forme poétique du muwašša arabo-andalou. La tašyi’a (également appelée bāzkišt), tout comme le prélude țariqa, encadre les différentes sections des formes vocales majeures arabes et persanes des $\mathrm{XIV}^{\mathrm{e}}-\mathrm{XV}^{\mathrm{e}}$ siècles.

Plus généralement, l'accompagnement du chant et les répliques instrumentales sont regroupés depuis le Moyen Age sous le terme générique de muāsaba. Cette dernière comprend réplique instrumentale en écho ou imitation, nommée tarğama, et ritournelle, comme elle intègre l'interpolation instrumentale d'incises mélodiques et rythmiques, ou mizzān, que l'on rencontre dans les formes vocales majeures de la Nahḍa. Tarğama, ritournelle et mizān sont souvent pareillement appelés lāzima mūsíqiyya (Helou 1972: 180).

Dans un autre registre, on parlera d'inšād instrumental. Ainsi, les formes précomposées et mesurées de musique instrumentale ottomane, pišrū ou pešrev (bašraf en arabe) et semā’’ ( sama $\bar{a} \bar{\imath})$, dérivent de formes à caractère strophique.

Le pišrū, aux XIV $\mathrm{XVV}^{\mathrm{e}}$ siècles, est soit chanté (généralement) sans texte (onomatopées), soit joué par des instrumentistes. Il comporte des strophes instrumentales en nombre impair qui alternent avec une ritournelle appelée tarğı̉ band, ou sar-band pišrū (Erlanger 1939: 245).

Quant au semāâ instrumental, il dérive des semāồ vocaux, hymnes mystiques employées dans le cadre de la cérémonie musicale āyīn ou a’ôn, appartenant au genre du samā' ou concert mystique, propre à la confrérie des Mevlevi (Feldman s.d.: 9). Une transe communielle ritualisée (danse giratoire) à induction et conduite musicales est l'aboutissement habituel de ce type de séances (Rouget 1980: 391-393, During 1988: 174-185).

51 Plus récemment, la forme musicale de ces compositions fait alterner quatre modules mélodiques - les hāanăt (sing. hāna) - avec la ritournelle taslimm: K1TK2TK3TK4T. Ces formes sont introduites en Syrie et en Egypte au cours du XIX ${ }^{e}$ siècle, et adoptées par les tahl-s ou consorts instrumentaux arabes de la Nahḍa, moyennant leur adaptation aux 
genres mélodiques arabes. Leur exécution au cours d'une wașla peut être assimilée à une forme d'inšăd instrumental, sorte de muwašša ou de beste à ritournelle et sans paroles.

Par ailleurs et en musique instrumentale traditionnelle populaire, la ritournelle läzima mūsīqiyya constitue la base autour de laquelle s'élabore le phrasé. La référence à la danse est claire. L'aspect répétitif de ces ritournelles instrumentales n'est pas sans rappeler les rituels populaires de transe cathartique à induction musicale pratiqués en Egypte, notamment dans le cadre du Zār et des lamentations funèbres, réminiscence de pratiques païennes anciennes (Lagrange 1994: 29-34).

La stylisation de ces séquences, dans un contexte artistique non ritualisé, conduit à des formes instrumentales équivalentes à la psalmodie responsoriale, dans laquelle des formulations de type cantillatoire mesuré improvisées alternent avec des réponses collectives, éventuellement avec des ritournelles à part entière. La forme du hawẩ (aérien), avec ses arabesques énoncées avec fantaisie et à tour de rôle par les musiciens, semble répondre à ce profil aux XIV $\mathrm{XVV}^{\mathrm{e}}$ siècles (Erlanger 1939: 245). On retrouve une démarche analogue dans la forme ottomane du pešrev karabatak, apparue au XVIII ${ }^{\mathrm{e}}$ siècle et qui repose sur l'alternance entre les énoncés instrumentaux solo et tutti (Feldman s.d.: 30). De même, pour la tahmila, forme instrumentale improvisative originale de la tradition musicale artistique issue de la Nahḍa en Egypte, qui présente un système d'improvisation interpolée en responsorial.

\section{Types d'improvisation}

Partant des analyses précédentes, l'improvisation emprunte, dans le cadre de la tradition musicale savante de l'Orient arabe, trois itinéraires ou types distincts:

1. L'improvisation monomodulaire consiste en la formulation de variations autour d'un phrasé précomposé et mesuré. Ces variations sont le plus souvent ornementales, comme dans les chants à caractère strophique ou hymnique (muwaššă), et leurs équivalents instrumentaux (bašraf et samāî). Elles peuvent devenir structurales par diminution, augmentation et autres procédés similaires entraînant ainsi un jeu hétérophonique fort apprécié.

\begin{tabular}{|c|c|c|c|c|c|c|}
\hline Prototype & cantillation & hybride & Prototype & cantillation & hybride & ritournelle \\
\hline Rythme & $\begin{array}{l}\text { verbal } \\
\text { anisochrone } \\
\text { (non mesuré) }\end{array}$ & $\begin{array}{l}\text { verbal, parfois } \\
\text { isochrone } \\
\text { (mesuré) }\end{array}$ & $\begin{array}{l}\text { verbal } \\
\text { isochrone } \\
\text { (mesuré) }\end{array}$ & $\begin{array}{l}\text { gestuel } \\
\text { intégrant le } \\
\text { verbal }\end{array}$ & $\begin{array}{l}\text { gestuel } \\
\text { intégrant le } \\
\text { verbal }\end{array}$ & $\begin{array}{l}\text { gestuel, } \\
\text { strictement } \\
\text { mesuré }\end{array}$ \\
\hline $\begin{array}{ll}\text { Caractère } & \\
\text { dominant } & \\
\text { verbal } & \text { ou } \\
\text { gestuel } & \end{array}$ & verbal & verbal & verbal & $\begin{array}{l}\text { Equilibre } \\
\text { verbal/gestuel }\end{array}$ & gestuel & gestuel \\
\hline $\begin{array}{l}\text { Caractère } \\
\text { dominant } \\
\text { verbal } \\
\text { musical }\end{array}$ & verbal & verbal & verbal & musical & musical & musical \\
\hline
\end{tabular}




\begin{tabular}{|c|c|c|c|c|c|c|}
\hline $\begin{array}{l}\text { Caractère } \\
\text { dominant vocal } \\
\text { ou } \\
\text { instrumental }\end{array}$ & vocal & instrumental & vocal & $\begin{array}{l}\text { vocal ou } \\
\text { instrumental }\end{array}$ & $\begin{array}{l}\text { vocal ou } \\
\text { instrumental }\end{array}$ & instrumental \\
\hline $\begin{array}{l}\text { Rapport au } \\
\text { sacré }\end{array}$ & sacré, spirituel & spirituel & spirituel & rituel & rituel & profane \\
\hline $\begin{array}{l}\text { Tendance } \\
\text { sacrale } \\
\text { originaire }\end{array}$ & monothéisme & monothéisme & monothéisme & $\begin{array}{l}\text { monothéisme } \\
\text { (aspects } \\
\text { rituels) }\end{array}$ & $\begin{array}{l}\text { monothéisme } \\
\text { (aspects rituels) } \\
\text { de même que } \\
\text { paganisme }\end{array}$ & $\begin{array}{l}\text { paganisme, } \\
\text { profane }\end{array}$ \\
\hline Effectif engagé & solo & solo & $\begin{array}{l}\text { solo plus ou } \\
\text { moins } \\
\text { responsorial } \\
\text { solo/tutti }\end{array}$ & $\begin{array}{l}\text { Responsorial } \\
\text { solo/tutti }\end{array}$ & tutti & tutti \\
\hline $\begin{array}{l}\text { Type } \\
\text { d'improvisation }\end{array}$ & $\begin{array}{l}\text { cantillatoire } \\
\text { plurimodulaire } \\
\text { en parcours } \\
\text { obligé modal }\end{array}$ & $\begin{array}{l}\text { cantillatoire } \\
\text { plurimodulaire } \\
\text { en parcours } \\
\text { obligé modal }\end{array}$ & $\begin{array}{l}\text { cantillatoire } \\
\text { plurimodulaire } \\
\text { en parcours } \\
\text { obligé modal }\end{array}$ & $\begin{array}{l}\text { plurimodulaire } \\
\text { par } \\
\text { interpolation } \\
\text { via } \\
\text { responsorial }\end{array}$ & $\begin{array}{l}\text { variation } \\
\text { monomodulaire, } \\
\text { parfois } \\
\text { plurimodulaire } \\
\text { par } \\
\text { interpolation }\end{array}$ & $\begin{array}{l}\text { variation } \\
\text { monomodulaire }\end{array}$ \\
\hline $\begin{array}{l}\text { Approche du } \\
\text { mode }\end{array}$ & $\begin{array}{l}\text { figuration } \\
\text { progressive } \\
\text { par paliers }\end{array}$ & $\begin{array}{l}\text { figuration } \\
\text { progressive } \\
\text { par paliers }\end{array}$ & $\begin{array}{l}\text { figuration } \\
\text { progressive } \\
\text { par paliers }\end{array}$ & $\begin{array}{l}\text { déroulement } \\
\text { rapide de } \\
\text { l'échelle } \\
\text { modale }\end{array}$ & $\begin{array}{l}\text { déroulement } \\
\text { rapide de } \\
\text { l'échelle modale }\end{array}$ & $\begin{array}{l}\text { déroulement } \\
\text { rapide de } \\
\text { l'échelle } \\
\text { modale }\end{array}$ \\
\hline Langue & $\begin{array}{l}\text { arabe } \\
\text { classique }\end{array}$ & instrumental & $\begin{array}{l}\text { arabe } \\
\text { classique }\end{array}$ & $\begin{array}{l}\text { arabe } \\
\text { classique ou } \\
\text { arabe dialectal }\end{array}$ & $\begin{array}{l}\text { arabe classique } \\
\text { ou arabe } \\
\text { dialectal }\end{array}$ & instrumental \\
\hline $\begin{array}{l}\text { Effet } \\
\text { psychologique } \\
\text { ou spirituel s'il } \\
\text { y a lieu }\end{array}$ & extase & extase & extase & transe & transe & transe \\
\hline
\end{tabular}

2. L'improvisation plurimodulaire à caractère cantillatoire repose avant tout sur l'habillage mélodique du grand nombre de modules métriques figurant dans les phrases d'un texte ainsi traité, que le microrythme verbal soit couplé ou non à un macrorythme cyclique. Il s'agit de la mise en correspondance entre les éléments mélodiques de la matrice modale choisie et ceux des modules rythmiques. Cette surjection s'appuie sur le grand degré d'assimilation du répertoire modèle de référence par le performeur qui s'en inspire pour élaborer sur le champ de nouveaux énoncés.

En l'absence de paroles chantées, l'instrumentiste qui improvise un taqsìm débite son phrasé selon un module métrique verbal implicite, comme s'il conservait de ces syllabes idéelles (imaginales) seulement leurs durées ou leurs poids respectifs: une sorte 
d'articulation mélodique et métrique verbale sans parole. Souvent, l'improvisation de type cantillatoire est brève: une phrase musicale correspondant à un verset ou à un vers, insérée entre des séquences modulaires.

Ce type d'énoncé peut s'élaborer dans d'autres cas sur un temps prolongé pour constituer une séquence musicale à part entière. Les phases successives ainsi constituées s'organisent alors selon un schéma de parcours obligé axé sur une figuration progressive, par seuils ou paliers, de l'architecture modale choisie. Telle phase est axée sur tel degré pivot, se déroule dans tel registre tétracordal, ou esquisse une modulation (talwin) particulière. Le parcours peut être exhaustif, tout comme il peut rester sélectif, mais l'ordre chronologique des phases est généralement respecté.

3. L'improvisation plurimodulaire d'interpolation consiste en la formulation de nouvelles phrases qui s'intercalent entre des phrases précomposées. Il s'agit du procédé de l'istirsāl décrit par Salwa El-Shawan (1987: 152) en ces termes: "nouvelles sections dérivant du lạn [mélodie initiale], introduisant de nouvelles idées mélodiques sur le même texte ou bien une nouvelle version du lan, consistant en un nouvel agencement de ses éléments lexicaux.». Dans le cas d'un responsorial à ritournelle(s), le soliste énonce de nouvelles phrases sur le texte (versets ou strophes) préétabli, auxquelles répond la ritournelle du chœur. La forme responsoriale instrumentale de la tahmila, apparue en Egypte à la fin du XIX ${ }^{\mathrm{e}}$ siècle, donne lieu à l'improvisation en solo de nouvelles phrases encadrées par la lāzima mūsīqiyya.

Que les phrases soient vocales ou instrumentales, le procédé de leur formulation improvisée s'appuie sur trois modèles:

- celui des modules précomposés de cantillation strophique mesurée, avec lequel il entretient des rapports de variation et de différenciation (ce qui ramène partiellement ou provisoirement à une improvisation monomodulaire);

- celui de la ritournelle, notamment sa conclusion cadentielle qafla dont il s'inspire pour fabriquer les cadences des phrases intercalaires;

- celui de l'improvisation plurimodulaire à caractère cantillatoire.

61 Les phrases interpolées sont ainsi fabriquées selon un schéma composite dans lequel peut prédominer l'influence de l'un des trois modèles précités. Le tableau ci-contre vise à établir une synthèse de la typologie présentée ci-dessus, en prélude à l'examen des formes musicales de la tradition émergée en Egypte au cours de la Nahḍa.

\section{Formes musicales traditionnelles sectorielles originelles}

62 L'invention de la nouvelle tradition musicale artistique de l'Egypte à l'époque de la Nahḍa s'est effectuée à partir d'une réalité complexe et contrastée, étant donné que les quatre secteurs traditionnels auxquels les pionniers ont fait appel étaient en situation de cloisonnement relatif (al-Muwayliḥī 1902: 406-407 et al-Hֵula’ì 1904-1906: 142).

\section{Secteur autochtone des traditions populaires profanes}

Milieu dont est issu 'Abduh al-Hāmūlī, la corporation citadine des ālātiyya regroupe les musiciens professionnels citadins profanes (chanteurs et instrumentistes), qui 
interprètent (lors de festivités privées) un répertoire musical populaire pouvant verser dans la musique d'art (Lagrange 1994: 29-34).

Le système mélodique de cette tradition est semblable à celui des autres traditions citadines populaires du Levant et de la Péninsule arabique, qui privilégient totalement le genre mélodique zalzalien, caractérisé par la présence dans un tétracorde de deux secondes neutres (Abou Mrad 2003: 715-716). Le genre diatonique, plus rare, présente un très fort resserrement du semi-ton, alors que le genre chromatique présente, à l'inverse, un élargissement des semi-tons. On retrouve totalement ces schémas structuraux mélodiques dans le répertoire modèle issu de la Nahḍa. Quant aux structures modales ( naġamāt) de la tradition populaire citadine initiale, elles sont au nombre de sept: rāst, bayyātīi, sỉkāh, șabā, ijiāz, 'uşşāq (mașî̀), jhārkāh (baladī).

Le répertoire traditionnel égyptien populaire citadin repose sur deux formes autochtones, dawr et mawwāl (voir supra) primitifs et intègre le muwaşşa chanté alépin, dans une mouture simplifiée.

A l'instar de la țaqțūqa, le dawr primitif se présente comme une précomposition vocale à partir d'un poème en langue vernaculaire et sur cycle binaire, à forme bipartite comprenant un madhab et un guṣn ou dawr proprement dit, mais, à la différence de la țaqț̄qqa (qui du reste est réservée aux chanteuses almées au XIX ${ }^{\mathrm{e}}$ siècle), le madhab est monomodulaire fixe et ne se répète pas comme un refrain, tandis que le guṣn ou dawr tolére des variations ornementales et structurales.

Quant au mawwāl primitif, il s'agit de la cantillation semi improvisative et non mesurée d'un poème dialectal, souvent précédé d'un istihlāl mélismatique improvisé sur les deux expressions « Yã leylì (Ma nuit!) et « Yã 'eynī» (Mes yeux!).

\section{Secteur autochtone des traditions musicales religieuses à caractère savant}

68 Les chanteurs engagés dans l'école de la Nahḍa ont, dans leur immense majorité, reçu la formation de cantillateur ( $\left.q \bar{a} r^{\prime}\right)$ et de mu'addin, préposé à l'appel à la prière ( $a d \bar{d} \bar{a} n$, cantillation mélismatique non mesurée et stéréotypée). Par ailleurs, les chantres religieux et parareligieux citadins égyptiens, non spécialisés dans la cantillation coranique, ont gravité depuis le milieu du XIXe siècle dans un milieu intermédiaire entre islam officiel et confréries soufies. Certains étaient attachés à une seule confrérie, d'autres, parvenus à une très grande maitrise artistique, demeuraient indépendants et s'adonnaient parfois au répertoire musical citadin profane, comme les deux célèbres cheikhs Yūsuf al-Manyalāwī (1847-1911) et Salāmah Ḥigāzī (1852-1917), devenus partie intégrante de la mouvance d'al-Ḥāmūlī et contributeurs essentiels de sa réforme (Lagrange 1996: ch. II).

En dehors des séquences rituelles des confréries, les hymnodes (munšidūn) pratiquent deux types de chant:

- la cantillation de l'ibtihāl, suppliques et oraisons en prose, et de la qaṣî̀a'alā lạnin mursal, poème religieux apologétique (madị nabawī - louange au Prophète) ou poème mystique;

- le genre hymnique, dont la forme est le muwašša à thématique religieuse (souvent madị nabawī) ou mystique, qui se calque d'un point de vue musical sur le répertoire des muwaşş ahātalépins égyptianisés, précomposés sur cycles rythmiques, toutefois sans l'accompagnement de la percussion, mais avec introduction d'un responsorial avec le petit chœur de la bițāna. 


\section{Secteur de la tradition musicale savante alépine}

La forme du muwašša chanté alépin s'est incrustée dans le paysage musical égyptien depuis le XVIII ${ }^{e}$ siècle, via les vagues successives de migration des musiciens d'Alep, comme le légendaire Šākir al-Ḥalabī (XVIII ${ }^{\mathrm{e}}$ siècle), de Damas, comme Abū Khalīl alQabbānī (XIX ${ }^{e}$ siècle), et de Mossoul, essentiellement Mollah 'Uțān al-Mawșilī (1845-1923), chantre, poète et homme politique iraqien, qui a influencé plusieurs artistes syriens et égyptiens (Hassan 2003: 104-113). Certains milieux d'érudits musicaux et poétiques égyptiens sont devenus des dépositaires jaloux de cette forme, comme Mụammad Šihāb a-d-Dīn, auteur d'une fameuse anthologie ${ }^{20}$ du muwašša.

Fig. 2: Un taht du début du XXe siècle rassemblant, autour du cheikh Yūsuf al-Manyalāwī, le joueur de qānūn Mohamad al-'Aqqād, le violoniste Ibrahim Sahlūn, le joueur de nāy Ali Saleh, le chanteur, Ali Abd el-Bārī et le joueur de riqq Mohamad Abū Kāmil

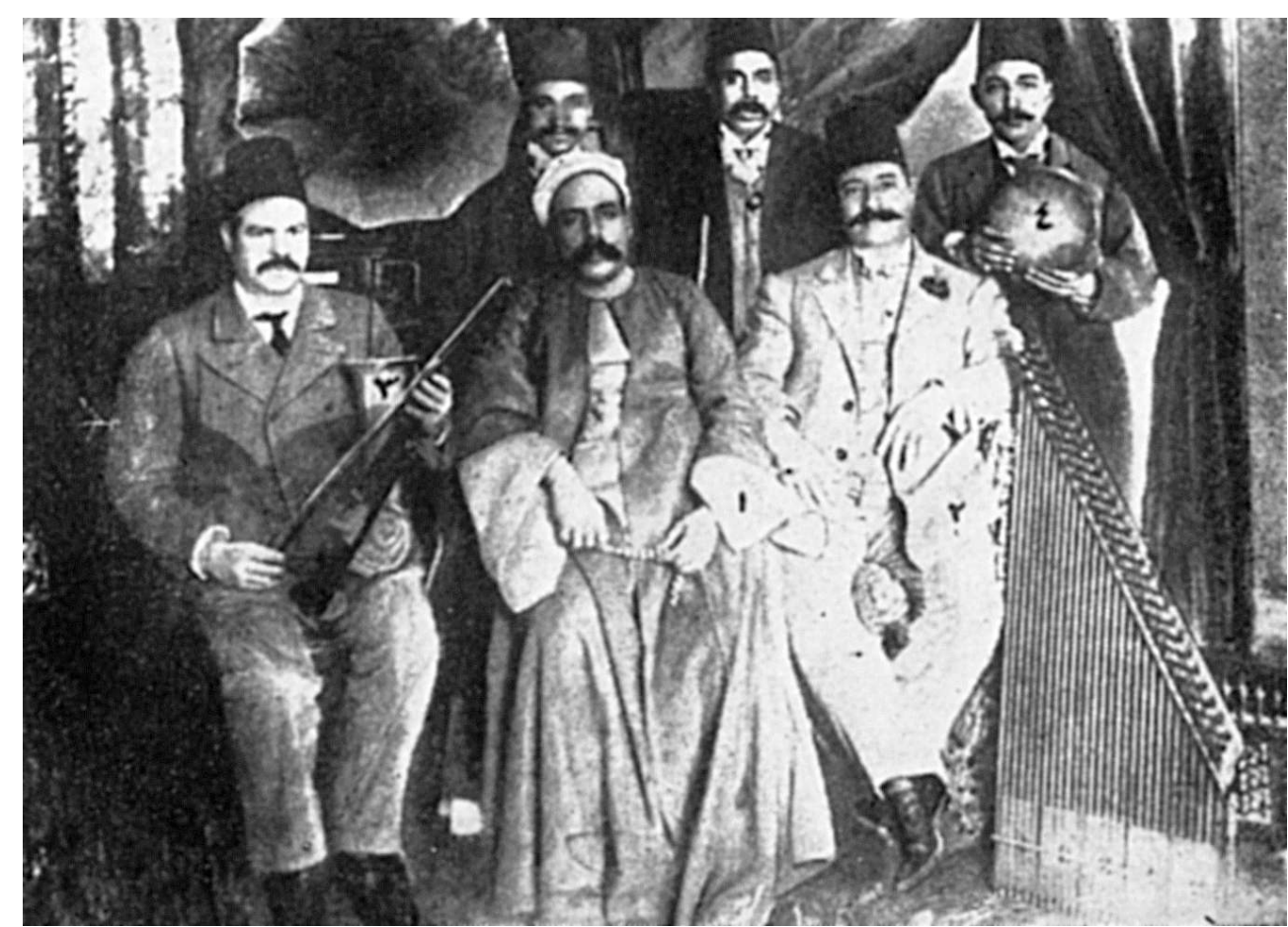

\section{Secteur de la tradition musicale savante ottomane}

71 La tradition musicale savante ottomane est présente à la cour des khédives et dans les palais de la noblesse locale. Elle est cultivée par des instrumentistes et des chanteurs turcs, grecs et arméniens. Les musiciens de l'école de la Nahḍa la découvrent par la fréquentation des concerts cairotes des artistes ottomans, ainsi que grâce aux séjours effectués à Istanbul par Hāmūlī et ses collègues.

72 Issu, tout comme les traditions musicales arabes, du tronc commun médiéval, l'art musical ottoman présente au XIX ${ }^{\mathrm{e}}$ siècle quatre grandes divergences avec son homologue arabe:

1. Sur le plan des échelles mélodiques: depuis la seconde moitié du XVIII ${ }^{\mathrm{e}}$ siècle les Ottomans ont substitué aux intervalles neutres du genre mélodique zalzalien leurs 
homologues de l'échelle dite naturelle (Feldman s.d.: 13, During 1994: 149 et Yakta 1921: 2945-3064).

2. Sur le plan modal: les milieux musicaux d'Istanbul et, dans une moindre mesure, ceux d'Alep, ont développé au cours des XVII ${ }^{\mathrm{e}}$-XVIII ${ }^{\mathrm{e}}$ siècles la typologie modale des maqāmāt (sing. maqām) dans le sens de la combinaison des genres entre eux, créant des structures modales composites ou tarākïb, et dans le sens de la transposition (Feldman s.d.: 13 et Moussali s.d.), loin du caractère cellulaire de pratique modale des sphères culturelles arabes (à part Alep) et iranienne.

3. Sur le plan rythmique: en dehors du taksim et de quelques formes de chant de derviches, les formes musicales ottomanes reposent, pour l'essentiel, sur le système des cycles rythmiques ușūl, poussé bien au-delà de ses limites (Feldman s.d.: 13).

4. Sur le plan des formes instrumentales: la tradition ottomane, notamment dans sa composante confrérique, a traité la musique instrumentale d'une manière autonome par rapport à la voix, tandis que les Arabes l'ont longtemps cantonnée dans un rôle subalterne face à la musicalisation du verbe.

La musique ottomane a exercé auprès des musiciens arabes du XIX ${ }^{\mathrm{e}}$ siècle, et notamment les Egyptiens de la cour du khédive Ismaël, le rôle de modèle prestigieux à suivre pour développer leur propre musique dans le sens d'une musique savante après des siècles de torpeur. Conscients des démarcations qui se sont installées entre les deux traditions au cours des $\mathrm{XVII}^{\mathrm{e}}$ et XVIII ${ }^{\mathrm{e}}$ siècles, les musiciens arabes ont limité l'adaptation d'éléments ottomans au strict minimum (quelques structures modales, quelques cycles rythmiques et quelques ouvertures instrumentales). En d'autres mots: la musique d'Istanbul n'a pas servi de « donneur d'organes» à l'égard de sa cousine du Caire.

\section{Configuration de la nouvelle tradition}

L'émergence au XIX ${ }^{\mathrm{e}}$ siècle de la nouvelle tradition arabe égyptienne n'a pas consisté en un syncrétisme de compilation, mais en un développement de structures mélodiques, rythmiques et formelles, souvent hybrides, mais enracinées dans la culture autochtone.

\section{Système mélodique}

L'intégration progressive de quelques structures modales ottomanes au système mélodique propre à la tradition citadine égyptienne s'est opérée moyennant la conformation des nuances d'intonation de leurs échelles aux idiosyncrasies locales, c'està-dire: affirmation du genre zalzalien dans sa nuance médiévale, resserrement du semiton dans le genre diatonique et son élargissement dans le genre chromatique. Le nouveau système modal comporte un plus grand nombre de maqāmāt (une trentaine) que les sept naġamāt originaires égyptiennes; mais tous les modes (autochtones et importés) se déclinent selon la typologie locale qui reflète le système Abbasside des doigtés et des courses, bien plus que les spéculations combinatoires d'Istanbul.

\section{Système rythmique}

La nouvelle musique savante arabe a certes incorporé à son système macrorythmique quelques usūl ottomans, mais le goût des musiciens égyptiens et levantins (hormis les Alépins) est resté réservé (pour ne pas dire réfractaire) à cet égard ${ }^{21}$. La seule complexité 
rythmique qui paraît avoir intéressé ces artistes est celle, microrythmique, du débit des valeurs temporelles relatives des sons mélodiques successifs, autrement dit le rythme métrique ou verbal.

\section{Instrumentaire et hétérophonie}

La performance est assurée par le taht, terme qui désigne un ensemble de solistes, à géométrie variable. En règle générale, si l'on se réfère aux enregistrements du début du $\mathrm{XX}^{\mathrm{e}}$ siècle, le taht instrumental typique est constitué par l'association d'un joueur de qānūn (cithare tabulaire trapézoïdale) et d'un violoniste ${ }^{22}$, souvent rejoints par un ' $\bar{u} d$ (luth à manche court) et parfois par un nāy (flûte oblique en roseau). La percussion consiste en un riqq (tambour sur cadre circulaire doté de cymbalettes) fort discret (Lagrange 1996, 83-86).

78 Aucun instrument n'est doublé, car chaque musicien doit pouvoir improviser en toute autonomie ses propres variantes du phrasé musical, et ce parallèlement aux versions proposées par des partenaires jouant d'instruments différents. La concomitance de l'énoncé de plusieurs variantes permet de constituer un tissu de phrasés hétérophoniques fort apprécié dans cette tradition, ce qui constitue l'un des traits essentiels de l'esthétique de la performance du taht de la Nahḍa.

79 La partie vocale est assumée par un chanteur soliste qui peut être secondé, pour les séquences à caractère hymnique et responsorial, par deux ou trois chanteurs de soutien ( sannìda, madhabjiyya ou muraddidūn). Ceux-ci sont chargés d'entonner tantôt des sujets précomposés (sections monomodulaires introductives de dawr ou de muwaššă), autour desquels le soliste brode en hétérophonie, tantôt des ritournelles servant d'assise modulaire au responsorial improvisatif "en tuilage», désigné par hank, qui est de mise dans les formes réactualisées du dawr et du muwaššạ.

\section{La wașla}

80 La relance endogène de la créativité s'est traduite par une forte propension à l'improvisation dans la performance tant des séquences issues des secteurs originels que de celles dont la forme a été mise au point dans le cadre de la Nahḍa musicale. Ces séquences, associées à leurs répertoires modèles respectifs, sont données successivement à entendre en performance, au sein de macrostructures formelles axées chacune sur un mode mélodique et désignées chacune par wașla (pl. waṣlāt). Une à trois waṣlāt, de durées variables (de vingt à soixante minutes chacune) et séparées par des temps de repos, constituent une performance type assurée par un chanteur et son taht. Trois phases jalonnent le parcours d'une waṣla: la phase des séquences monomodulaires mesurées et précomposées, celle des séquences plurimodulaires cantillatoires non mesurées et improvisées, et celle des séquences mixtes responsoriales mesurées à interpolation improvisée.

81 La première phase d'une waṣla est celle des séquences monomodulaires entièrement précomposées, de genre hymnique ou strophique, admettant souvent des ritournelles. Il s'agit d'une ouverture instrumentale suivie d'une ouverture vocale.

- L'ouverture instrumentale, destinée principalement à l'échauffement et au repérage modal, consiste tantôt en une pièce ottomane arabisée (plus rarement, composition arabe suivant une forme ottomane), bašraf, alias pešrev, ou sama $\bar{a}^{\natural} \bar{l}$, et tantôt en une séquence de forme 
originaire arabe, dūlāb, court prélude permettant de résumer toute la phase d'ouverture ou bien et à titre exceptionnel, tạmila, séquence responsoriale faisant alterner ritournelles en tutti et improvisations en solo.

- L'ouverture vocale, destinée principalement à la mise en voix et au repérage modal, consiste en un muwašša chanté alépin égyptiannisé, ou en une succession restreinte de muwaššăāt.

La deuxième phase d'une wașla est celle des séquences plurimodulaires cantillatoires non mesurées et improvisées en solo instrumental (taqsìm) ou en solo vocal (tafrīd) à répliques instrumentales.

- Taqsīm (pl. taqāsìm): énoncé instrumental en solo qui précède et encadre la cantillation vocale par un prélude et des reproductions instrumentales des énoncés vocaux en écho.

- Yā leyl (layālì): improvisation mélismatique qui précède en général la récitation mélodieuse d'un poème.

- Mawwāl « nouvelle manière»: cantillation poétique en langue vernaculaire, plus élaborée que son prototype populaire et s'inscrivant dans une optique de musique savante.

- Qașìda 'alā lạnin mursal: cantillation poétique en arabe classique.

83 La troisième phase d'une wașla est celle des séquences mixtes responsoriales mesurées à interpolation improvisée. Un dawr (ou dōr) «nouvelle manière», ou bien une qașïa muwa qqa'a (cantillation mesurée d'un poème classique sur le cycle binaire de la waḥda avec interférence d'une ritournelle hétérogène) conclut la wașla. Ces deux formes sont analysées plus loin. Notons que la forme de la tạmila appartient de plein droit à cette catégorie et qu'elle peut conclure une waṣla strictement instrumentale, exceptionnelle au $\mathrm{XIX}^{\mathrm{e}}$ siècle, mais reflétée dans les enregistrements du début du XX $\mathrm{XX}^{\mathrm{e}}$ siècle ${ }^{23}$, et ce au même titre que le dawr, son équivalent vocal.

84 Tandis que Salwa El-Shawan (1987: 153) se contente de l'expression "succession d'improvisations et de compositions vocales et instrumentales sur le même maqām» pour décrire la wașla, Frédéric Lagrange (1996) rattache celle-ci au «schème universel de la suite musicale».

\begin{tabular}{|c|c|c|c|c|}
\hline Phase & \multicolumn{2}{|l|}{1} & 2 & 3 \\
\hline Argument & \multicolumn{2}{|l|}{ thèse } & antithèse & synthèse \\
\hline $\begin{array}{l}\text { Prototype } \\
\text { formel }\end{array}$ & \multicolumn{2}{|l|}{ ritournelle, hymne } & cantillation & mixte, responsorial \\
\hline $\begin{array}{l}\text { Type } \\
\text { d'élaboration }\end{array}$ & \multicolumn{2}{|l|}{ précomposition } & improvisation & mixte \\
\hline $\begin{array}{l}\text { Modèle } \\
\text { d'improvisation } \\
\text { s'il y a lieu }\end{array}$ & \multicolumn{2}{|c|}{ monomodulaire à variation } & $\begin{array}{l}\text { plurimodulaire à } \\
\text { cantillation }\end{array}$ & Plurimodulaire à interpolation \\
\hline $\begin{array}{l}\text { Caractère } \\
\text { rythmique }\end{array}$ & \multicolumn{2}{|c|}{$\begin{array}{l}\text { mesuré à cycle rythmique } \\
\text { souvent complexe }\end{array}$} & Non mesuré & Mesuré à cycle rythmique simple \\
\hline $\begin{array}{l}\text { Origine } \\
\text { géographique }\end{array}$ & alépine ottomane & autochtone & autochtone & autochtone \\
\hline
\end{tabular}




\begin{tabular}{|c|c|c|c|c|c|c|c|c|}
\hline $\begin{array}{l}\text { Tradition } \\
\text { originaire }\end{array}$ & $\begin{array}{l}\text { savante } \\
\text { profane }\end{array}$ & $\begin{array}{l}\text { savante } \\
\text { spirituelle }\end{array}$ & $\begin{array}{l}\text { populaire } \\
\text { citadine } \\
\text { profane }\end{array}$ & $\begin{array}{l}\text { populaire } \\
\text { citadine } \\
\text { profane }\end{array}$ & $\begin{array}{l}\text { savante } \\
\text { spirituelle }\end{array}$ & $\begin{array}{l}\text { populaire } \\
\text { artistique } \\
\text { citadine } \\
\text { profane }\end{array}$ & $\begin{array}{l}\text { savante } \\
\text { profane }\end{array}$ & \begin{tabular}{|l} 
savante \\
spirituelle
\end{tabular} \\
\hline $\begin{array}{l}\text { Genre } \\
\text { instrumental }\end{array}$ & & $\begin{array}{l}\text { bašraf, } \\
\text { samā'‘i }\end{array}$ & dūlāb & & taqsīm & $\begin{array}{l}\text { tạmīla, } \\
\text { taqsīm } \\
\text { dansant }\end{array}$ & & taqsìm mesuré \\
\hline $\begin{array}{l}\text { Genre vocal } \\
\text { en dialecte }\end{array}$ & & & & $\begin{array}{l}\text { mawwāl, } \\
\text { «Yā } \\
\text { leyl!» }\end{array}$ & & $\begin{array}{l}\text { dawr nouvelle } \\
\text { manière }\end{array}$ & & \\
\hline $\begin{array}{l}\text { Genre vocal } \\
\text { en arabe } \\
\text { classique }\end{array}$ & $\begin{array}{l}\text { muwaššạ } \\
\text { chanté }\end{array}$ & & & & $\begin{array}{l}\text { qașìda 'alā } \\
\text { lạnin } \\
\text { mursal }\end{array}$ & & $\begin{array}{l}\text { muwašša } \\
\text { responsorial }\end{array}$ & $\begin{array}{l}\text { qașīdamesurée } \\
\text { sur waḥda }\end{array}$ \\
\hline
\end{tabular}

De fait et à l'instar de la nawba abbasside, de la nawba arabo-andalouse, du fasl ottoman, de la qawma yéménite, et des nombreuses formes de suites en musique savante d'Europe occidentale, la wașla égyptienne applique la loi de l'unité modale, c'est-à-dire que toutes les séquences regroupées doivent s'appuyer sur une même structure modale de base, tolérant des modulations de proximité. Ces regroupements correspondent au concept de «forme construite» (Lambert 1997: 109), à celui de "compound-form-principle» (Racy 1980-1981-2003: 77-79, Al-Faruqi 1985: 3) et à la notion similaire de "modèle composite» (Lortat-Jacob 1987: 48): succession de modules différenciés unis par un paramètre temporel ou mélodique, en l'occurrence ici, le mode qui est fixe.

Mais, à la différence de ses homologues, la waṣla est une forme extrêmement variable dans sa composition à partir des séquences élémentaires. Elle répond encore mieux au modèle du " parcours obligé» au sens donné à cette expression par Bernard Lortat-Jacob ( ibid.: 54-57): suite non cyclique de variations modulaires à seuils permettant le passage, sans transition, d'une élaboration thématique à une autre fondamentalement différente.

Les séquences traditionnelles dont se constitue la wașla sont homogènes du point de vue de leur appartenance mélodique modale, laquelle constitue le modèle matriciel minimum, exprimable par l'énoncé d'un module restreint, tel que l'un des préludes dūlāb élaborés dans ledit mode, et qui correspond à une opération " plus petit dénominateur commun» (ppdc) du parcours (Lortat-Jacob ibid.: 48). Ces séquences sont en revanche hétérogènes en ce qui concerne le genre musical des séquences qui cohabitent au sein de chaque phase. De prime abord, le genre musical est fonction de l'émetteur sonore et obéit à la dialectique du vocal et de l'instrumental. Il est également fonction de la langue chantée, ce qui l'assujettit, au sein du vocal, à la dialectique linguistique opposant arabe classique et arabe vernaculaire. Cette première discrimination des genres traverse toutes les phases, puisque au moins deux de ces trois genres sont représentés au niveau de chaque phase du parcours de la wașla.

Face à l'unité modale qui traverse toutes les phases et face à la diversité des genres qui caractérise et la waṣla dans son ensemble et ses différentes phases, ces dernières semblent tenir leur légitimité de trois critères essentiels qui tendent à regrouper les séquences et à les ancrer dans leurs phases respectives: processus créatif mis en œuvre, caractère 
rythmique et origine culturelle. La forme musicale de chaque séquence parait résulter de la convergence de ces contraintes. Aussi l'aspect global du parcours obligé désigné par le terme wașla peut-il être identifié à une tentative de figurer un mode donné par une diversité de séquences compartimentées au sein des trois phases successives du parcours en fonction des critères de modèle d'élaboration, de rythmique et d'origine culturelle, au sein de la tradition musicale savante issue de la Nahḍa en Egypte. De fait, les critères permettant la discrimination des séquences musicales au sein de la wașla se déclinent chacun sous la forme d'une dialectique ternaire classique en thèse, antithèse et synthèse. Le tableau ci-contre met en relation ces différents paramètres.

Il convient de souligner qu'une wașla de concert (Hulaī 1904-1906: 89-91) comprend en général un ou deux éléments de chaque phase.

- Type de wașla axé sur le dawr: bašraf, muwaššạ, taqsīm, mawwāl, dawr.

- Type de waṣla axé sur la qaṣida: dūlāb, taqsīm, qaṣida 'alā lạnin mursal, qașīda mesurée sur waḥda.

Quant aux wașla-s des enregistrements sur 78 tours, les contraintes de durées les ont réduites au strict minimum afin de mettre en valeur l'une des phases, mawwāl, dawr ou qașida.

\section{Formes résultantes}

Les séquences constitutives d'une waṣla peuvent être réparties en deux catégories selon leur degré d'ancienneté (et de remaniement) par rapport au processus de remise à jour de la tradition arabe orientale, intervenu au cours du XIX ${ }^{e}$ siècle.

\section{Les formes anciennes peu remaniées}

La catégorie des formes anciennes peu remaniées regroupe les formes suivantes: ouvertures instrumentales ottomanes, bašraf, sama $\bar{a} \imath$, adaptées aux idiosyncrasies égyptiennes, muwašša chanté alépin et poésie classique cantillée non mesurée, qasiīa 'alā lạnin mursal.

\section{Les « néoformations»}

La catégorie des nouvelles formes et des formes anciennes fortement remaniées regroupe les formes suivantes: dūlāb, tạmila, mawwāl nouvelle manière, dawr nouvelle manière et qașida 'alā 'l-waḥda. Les deux dernières de ces formes sont décrites ci-après.

\section{Le dawr « nouvelle manière»}

94 Forme vocale à caractère partiellement hymnique, semi improvisée, en langue vernaculaire stylisée, mesurée, évoluant (en général ${ }^{24}$ ) sur un cycle rythmique binaire, le dawr comprend deux grandes sections:

a) Le madhab: entrée en matière ou exposition thématique fixe d'un point de vue mélodique, à caractère hymnique, le madhab suit un "modèle dense» à système monomodulaire. Hormis quelques variations ornementales, par diminution ou par déplacement des valeurs rythmiques et de l'accentuation (syncopes, contretemps), par 
lesquels l'énoncé du chanteur soliste engendre de l'hétérophonie en se démarquant de celui des chanteurs sannida, plus littéral, et de ceux des instrumentistes, plus enjoués, la performance de la section introductive demeure fidèle à l'énoncé du modèle précomposé.

b) Le dawr proprement dit, ou guṣn: passé le seuil de l'édifice, on entre en situation de "modèle lâche», puisque la seconde section est bâtie sur une succession d'éléments construits à partir du modèle initial, non pas en tant que variation sur un thème, mais au titre d'une improvisation plurimodulaire qui est, en appliquant le lexique de Bernard Lortat-Jacob (1987: 58), de type « meccano», à cycle, à seuils, à parcours obligé. Le guṣnn est construit en procédant par étapes successives et à partir d'éléments dissemblables créés en référence à certains segments choisis, souvent avec fantaisie, dans le canevas mélodique (lạn) du madhab, et appliqués à des fragments du texte du dawr proprement dit:

Istirsāl: La première étape consiste en une série de développements mélodiques partiellement improvisés et interpolés selon le procédé de l'istirsāl, s'appuyant sur des mots prélevés dans le premier vers du dawr, qui se transforment en micromodules métriques au sein desquels sont développés «en éventail» certains motifs mélodiques du lạn du madhab. Il s'agit d'une improvisation « de type « lego», sans cycle, à seuils diffus, à parcours obligé», selon le système de Lortat-Jacob (1987: 58), et ce au sein même du déroulement de type «meccano» de l'ensemble de la section du gușn.

Le début de cette première étape est marqué par l'énoncé du premier fragment mélodique du madhab adapté au texte du premier hémistiche du gușn. Le chanteur fragmente ensuite le texte et le traite d'une manière proche de la cantillation mélismatique mesurée qui met en valeur la prosodie métrique (rythme verbal) du texte sans toutefois se préoccuper de l'intelligibilité du sens. Les musiciens du taht répondent immédiatement à ces énoncés par une reproduction instrumentale (tarjama traduction) du phrasé vocal, laquelle permet de souligner le caractère cantillatoire du chant. D'autres fois, le taht intercale de courtes incises (mizān) qui soulignent le caractère mélodique modal des développements chantés tout en en marquant sur un plan rythmique les degrés pivots du phrasé.

97 Lorsque le dawr, parti d'une forme populaire répétitive, est parvenu à son stade de maturité, il a intégré, dans son parcours obligé de type "meccano», des phases remarquables par leur théâtralité:

- Āhāt: Les āhāt sont de longues plaintes sur l'onomatopée «āh!» à caractère mélismatique. Ces énoncés sont généralement appuyés, en tuilage, par des "sons filés» par paliers successifs, émis par les sannìda en contrepoint des envolées (parfois pathétiques) du soliste.

- Hank: Phase de chant responsorial, le hank, fait alterner ritournelles chantées par les sannīda et «salves» de phrasé improvisé par le soliste. Chaque ritournelle constitue un modèle micromodulaire métrico-mélodique dense à partir duquel se construit un responsorial dans lequel les sannìda se chargent de répéter le modèle d'une manière immuable et le soliste de l'énoncer en en respectant l'énoncé métrique, tout en en transformant totalement ou partiellement (généralement dans sa partie caudale) le phrasé mélodique. En ce sens la ritournelle joue le rôle crucial de matrice modulaire métrique des improvisations responsoriales.

100 -Hā̄tima: Phase conclusive, la Hẫtimaconsiste généralement en une reprise de la dernière partie de la mélodie du maḍhab sur le texte de la dernière partie du gușn. 


\section{La cantillation de la qạìda 'alā 'I-waḥda}

101 La qașida 'alā 'l-waḥda est un poème arabe classique cantillé sur une mélodie improvisée, selon un schéma d'exploration modale, et mesurée selon le cycle binaire simple de la waḩda. Pour chaque hémistiche, ou pour chaque vers du poème, est formulée une phrase mélodique entière qui expose une facette topologique du mode, ou exprime une phase d'un parcours obligé, selon des modèles exemplaires de déploiement du phrasé. Par moments, le chanteur s'empare d'un mot ou d'une syllabe pour leur faire porter des mélismes tarannumāt.

Cependant, la texture même du phrasé, notamment dans la formulation de ses cadences, et la tessiture de ses phrases, reflète l'inférence d'une mélodie récurrente autour de laquelle s'est construite cette forme. Il s'agit, en fait, d'une ritournelle vocale, devenue instrumentale, qui s'origine dans un madhabde dawr, devenu lāzimat al-'awāzil ou « ritournelle des censeurs» (Hula'î 1904-1906: 90, Lagrange 1994: 304 et Abou Mrad 2002: ch. V). Celle-ci était chantée au début et à la fin de la qașïda, avec récurrences instrumentales aux moments-clés du développement du phrasé vocal, en ponctuation et soulignement, en fait, en écho (ou plutôt en confirmation) des cadences importantes. Le phrasé vocal de la qașida a reçu, dès la naissance de cette forme, l'empreinte de cette ritournelle. Le rôle joué par cette dernière a fait de cette séquence une forme mixte à prédominance improvisative exploratoire articulée à une récurrence précomposée. À la fin des phrases vocales et lorsque la ritournelle n'est pas entonnée, les instrumentistes du taht formulent des incises ainsi que des reprises en écho de type tarjama.

\section{Conclusion}

103 Le processus de développement exogène, engagé dès la fin de la Grande Guerre par les musiciens modernistes égyptiens, libanais et syriens, a vite fait de substituer à cette musique d'art des expressions musicales légères, diversement teintées d'occidentalisme, ferment de cette musique de variété qui règne sans partage sur le paysage culturel arabe de la seconde moitié du XXe siècle.

Souvent accueillie en tant que "patrimoine» muséifié, la tradition musicale savante du Proche-Orient arabe survit depuis plusieurs décénies en retrait de la production artistique, dans le cadre de la musique sacrée, surtout la cantillation mélismatique du Coran, et dans de rares cercles musicaux « conservateurs».

Certains de ces milieux à caractère académique et divulgateur axent leurs efforts sur une restitution littéraliste d'un supposé «répertoire» définitif, fixé par la notation, qu'on livre en le simplifiant et l'amplifiant à un public de non-initiés (Lagrange 1996: 144). Faisant fi des normes traditionnelles de la performance musicale, qu'il s'agisse de l'intonation des intervalles, de la complexité du phrasé (notamment de l'ornementation), de la stylistique de l'art du soliste improvisateur ou de l'esthétique de la sonorité vocale et instrumentale traditionnelle, d'aucuns ${ }^{25}$ ont opté pour une interprétation de type orchestral et choral, à l'intonation inféodée au tempérament à vingt-quatre quarts de ton égaux, au phrasé figé et simplifié, tolérant arpèges et accords à la volée, et évacuant toute velléité improvisative. 

da réflexion nécessaire au travail actuellement effectif de relance de la pratique de cette tradition. L'apprentissage, notamment, est appelé à s'appuyer sur une réelle prise de conscience de l'origination des formes, alimentée par une connaissance approfondie des mécanismes d'élaboration du phrasé des séquences, ainsi que des liens mystérieux qui se nouent entre les modèles et leurs réalisations. Cette quête cognitive serait futile si elle n'était pas entreprise pour soutenir le cheminement initiatique de l'apprenti musiquant selon un (autre) parcours obligé en trois temps: imprégnation (à partir des modèles), herméneutique et accomplissement.

\section{BIBLIOGRAPHIE}

ABOU MRAD Nidaa, 1991, «L'Imâm et le chanteur: réformer de l'intérieur: une mise en parallèle de Muhammad 'Abduh et 'Abduh al-Hâmûlî», in « Dossier La Nahda et la musique», Les Cahiers de l'Orient 24. Paris: SFEIR.

ABOU MRAD Nidaa, 2002, Tradition musicale et renaissance de l'Orient arabe: esquisse d'une philologie mélodique, thèse de doctorat en Musicologie. Liban: Université Saint-Esprit de Kaslik.

ABOU MRAD Nidaa, 2003, «Scale melodiche e identità culturale nell'Oriente arabo» [Échelles mélodiques et identité culturelle en Orient arabe], Enciclopedia della musica, diretta da Jean-Jacques Nattiez III, Musica e culture. Torino: Einaudi: 697-731.

AL-FARUQI Lois Ibsen, 1985, « The Suite in Islamic History and Culture», The World of Music XXVII, 3.

AL-HֵULA'I Muhammad Kāmil, 1993 [1904-1905], Kitāb al-mūsīqī a-š-šarqī [Livre du Musicien oriental]; rééd: Le Caire: Maktabat a-d-Dār al-'arabiyyat li-l-kitāb.

AL-MUWAYLIHI Ibrāhīm, 1902, « 'Abduh al-Ḥāmūlī» in Jurjī Zaydān, Tarājim maşāhīr al-qarn a-ttāsi' 'aşar [Biographie des sommités du XIX siècle], réédité par Manşūrāt Dār maktabat al-Ḥayāt: 406-410.

AUBERT Laurent, 2001, La musique de l'autre, les nouveaux défis de l'ethnomusicologie, Genève \& Paris: Georg éditeur.

CHAILLEY Jacques, 1996, La musique et son langage. Paris: Editions Aug. Zurfluh.

CHALFOUN Alexandre (Iskandar Šalfūn), 1922, La musique égyptienne: Rapport sur sa situation en 1922. Le Caire. 
CHALFOUN Alexandre (Iskandar Šalfūn), 1922-1926, Revue Rawdiat al-balābil [Jardin des rossignols]. Le Caire.

CORBIN Solange, 1960-2000, l'Eglise à la conquête de sa musique. Paris: Gallimard, rééd. Liban: CEDLUSEK.

DELEUZE Gilles et Félix GUATTARI, 1980, Capitalisme et schizophrénie 2 - Mille plateaux. Paris: Les Editions de minuit.

DURING Jean, 1987, « Le point de vue du musicien: improvisation et communication», L'improvisation dans les musiques de tradition orale, ouvrage collectif (Bernard Lortat-Jacob, éditeur). Paris: SELAF: $33-44$.

DURING Jean, 1988, Musique et extase: L'audition mystique dans la tradition soufie. Paris: Albin Michel., 1991, Le répertoire-modèle de la musique iranienne: Radif de tar et de setar de Mirza ‘Abdollah, version de Nur ‘Ali Borumand. Teheran: Éditions Soroush.

DURING Jean, 1994, Quelque chose se passe: le sens de la tradition dans l'Orient musical. Lagrasse: Verdier.

EL-SHAWAN Salwa, 1987, « Aspects de l'improvisation dans la musique arabe d'Egypte», L'improvisation dans les musiques de tradition orale, ouvrage collectif (Bernard Lortat-Jacob, éditeur). Paris: SELAF: 152-157.

Encyclopédie de la musique, 1983-1992-1995, Rome: Garzanti Editore, Paris: Librairie générale française (Pochotèque).

ERLANGER Baron Rodolphe d', 1930-1959, La musique arabe, tomes I-VI. Paris: Paul Geuthner.

FARMER Henry George, 1926-1986, « The Influence of Music from Arabic Sources», Studies in Oriental Music, Université de Frankfurt, vol. 1.

FELDMAN Walter, s.d., "Ottoman Music», livret du coffret CD Ottoman turkish music anthology. Instanbul: Istanbul Metropolitan Municipality.

HASSAN Schéhérazade Q., 1987 «Le makām irakien: structures et réalisations», L'improvisation dans les musiques de tradition orale, ouvrage collectif (Bernard Lortat-Jacob, éditeur). Paris: SELAF: 143-149.

HASSAN Schéhérazade Q., 2003, « A-d-dīniy wa-d-dunyawī fí al-mūsīqā khilāl al-‘aşr al-Uțmānī almuta'akhir fi al-'Irāq, al-Mullā 'Uțmān al-Mawșilī namūdajan[Le religieux et le profane en musique en Iraq à la fin de l'époque ottomane, le modèle du Mullā 'Utmān al-Mawșilī] in A-n-nahḍa al-'arabiyya wa-l-mūsīqā: hૂayār a-t-tajdìd al-muta'așṣil[La Renaissance arabe et la musique: l'alternative du renouvellement endogène], Nidaa Abou Mrad (éditeur). Amman: Publications de l'Académie Arabe de musique.

HELOU Salīm, 1961-1972, Al-mūsīqā a-n-naẓariyya [La musique théorique]. Beyrouth: Dār Maktabat Al-Ḥayāt.

HOURANI Albert, 1962-1977, Arabic Thought in the Liberal Age 1796-1939, London: Oxford University Press, traduit de l'anglais en arabe par Azqoul: al-Fikr al-'arabi fi 'aşr a-n-nahdia. Beyrouth: Dar anNahar.

LAMBERT Jean, 1997, La médecine de l'âme. Nanterre: Société française d'ethnologie.

LAGRANGE Frédéric, 1994, Musiciens et poètes en Egypte au temps de la Nahda, thèse de doctorat. Paris: Université de Paris VIII, Saint-Denis. 
LAGRANGE Frédéric, 1996, Musiques d'Egypte [livre accompagné d'un CD anthologique]. Paris: Cité de la Musique/Actes Sud.

LORTAT-JACOB Bernard, 1987, «Improvisation: le modèle et ses réalisations», L'improvisation dans les musiques de tradition orale, ouvrage collectif (Bernard Lortat-Jacob, éditeur). Paris: SELAF: 45-59.

MASSAQAH Mīhnāyīl et Père RONZEVALLE, 1899, A-r-Risāla aššihābiyya fí a-ș-ṣināa a al-mūsīqiyya [Épître à l'Émir Chehab, relative à l'art musical], édition et commentaires du Père Louis Ronzevalle. Beyrouth: Imprimerie des Pères jésuites. Le premier manuscrit date de 1840. Eli Smith en fit paraitre une version anglaise dès 1849 , tandis que le Père Ronzevalle en publia une version française en 1913.

MOUSSALI Bernard, 1991, «L'école khédiviale» in « Dossier La Nahda et la musique», Les Cahiers de l'Orient 24. Paris: SFEIR: 175-184.

MOUSSALI Bernard, s.d., Le Congrès de musique arabe du Caire, ouvrage posthume en cours d'édition par les soins de Jean Lambert.

PEARSON Mike, 1996, «Réflexions sur l'ethnoscénologie», traduit de l'anglais par Pierre Bois, Internationale de l'imaginaire, nouvelle série, 5: « La scène et la terre»: 55-64.

POCHÉ Christian, 1995, Livret du CD Turquie, Archives de la musique turque, vol. 1 HM ADD, anthologie de 78 tours en CD, Ocora Radio France, Paris.

POCHÉ Christian, 1995, La musique arabo-andalouse. Paris: Cité de la Musique/Actes Sud.

RAAD Hasan, 2001, Al-Manhaj al-qawìm fì tilāwat al-Qur'ān al-karīm [La méthode directe d'apprentissage du saint Coran]. Beyrouth: Dār a-Ţ- Ţaqāfa al-islāmiyya.

RACY Ali Jihad, 1977, Musical Change and Commercial Recordings in Egypt, 1904-1932. Urbana: University of Illinois at Urbana-Champaign, Ph.D.

RACY Ali Jihad, 1980-1981-2003, « The Waslah: A Compound-Form Principle in Egyptian Music», Arab Studies Quarterly vol. V., No 4 (Fall): 396-403, article réédité en arabe en 1981 et 2003 « Alwașla: qālib murakkab fì al-mūsīqā al-mișriyya» [La wașla: une forme composite en musique égyptienne], A-n-nahḍa al-'arabiyya wa-l-mūsīqā: hayyār a-t-tajdìd al-muta'așșil [La Renaissance arabe et la musique: l'alternative du renouvellement endogène], Nidaa Abou Mrad (éditeur). Amman: Publications de l'Académie Arabe de musique.

REINACH Théodore, 1926, La Musique grecque. Paris: Payot - Éditions d'Aujourd'hui.

ROUGET Gilbert, 1980, La musique et la transe, esquisse d'une théorie générale des relations de la musique et de la possession. Paris: Gallimard.

SAYED Redouane, 2003, «a-t-Tajdīd fī 'l-fikr al-islāmī wa-mas'alat ru'yat al-‘ālam» [Le renouvellement de la pensée islamique et la question de la vision du monde], A-n-nahda al-'arabiyya wa-l-mūsīqā: hayār a-t-tajdīd al-muta'așșil [La Renaissance arabe et la musique: l'alternative du renouvellement endogène], Nidaa Abou Mrad (éditeur). Amman: Publications de l'Académie Arabe de musique.

SHILOAH Amnon, 1972, Al-Ḥasan ibn Ạmad ibn 'Alī al-Kātib, La Perfection des connaissances musicales. Paris: Librairie orientaliste Paul Geuthner.

SHILOAH Amnon, 1991, «La voix et les techniques vocales chez les Arabes», Cahiers de musiques traditionnelles 4, « Voix». Genève: Ateliers d'ethnomusicologie: 85-101.

SHILOAH Amnon, 2003, «Ebraismo e Islam: posizioni monoteistiche nei riguardi della musica» [Hébraïsme et Islam: attitudes monothéistes face à la musique], Enciclopedia della musica, diretta da Jean-Jacques Nattiez III, « Musica e culture». Torino: Einaudi: 313-339. 
TRAN Van Khé, 1971, «Les « Modes» en Afrique et en Asie», Bulletin du CEMO 7-8. Paris: CEMO.

Wright Owen, 1978, The modal system of Arab and Persian music 1250-1300. London: Oxford University Press.

YAKTA Ra'uf, 1921, « La musique turque» in Encyclopédie de la musique et dictionnaire du Conservatoire. Paris: Delagrave: 2945-3064.

\section{NOTES}

1. Terme emprunté à Laurent Aubert (2001: 38-39) et Pierre Bois (Pearson 1996: 55, n. 1) pour désigner ce qui est communément indiqué par les vocables exécution, interprétation et prestation.

2. La tradition musicale artistique alépine diffère radicalement de son homologue ottomane sur le plan verbal (arabe ou turc) et des formes vocales, avec la prédominance de la forme musicale du muwaşşa (séquence vocale dont le texte poétique arabe est multimètre et multirime). Elle s'en distingue également par son attachement à l'intonation arabe du genre mélodique zalzalien (Abou Mrad 2002: ch. III).

3. Ce terme désigne la période qui s'étend de la campagne d'Egypte (1798) et du règne de Muhammad 'Alī Pacha (1805-1848) à l'entre-deux guerres (Hourani 1962). La Nahḍa atteint néanmoins son apogée au cours de la seconde moitié du XIX ${ }^{\mathrm{e}}$ siècle.

4. Attitude se référant à un «Islam primordial» (salaf al-ummat) idéalisé.

5. «Ecole [de la Nahda] doit être compris ici dans le sens de communauté esthétique et stylistique dans la composition et l'interprétation.» (Lagrange 1996: 76-77). La mouvance d'alḤāmūlī comprend notamment les chanteurs et compositeurs Mụammad 'Uțmān, Yūsuf alManyalāwī, Salāmah Ḥigāzī, le joueur de qānūn Mụammad al-'Aqqād, le violoniste Ibrahim Sahlūn et le joueur de nāy Amīn al-Buzarī. Hormis Ḥāmūlīet 'Uțmān, des anthologies d'enregistrements 78 tours de ces artistes ont été republiées en $\mathrm{CD}$ au cours des quinze dernières années (Ocora Radio France et Club du Disque Arabe).

6. D'où l'expression « école khédiviale» proposée par Bernard Moussalli (1991).

7. Commencée par Mikhā’îl Maššāqah, la mise en théorie de cette tradition s'est poursuivie par Mụammad Kāmil al-Khula'î (1904-1906) et Alexandre Chalfoun (1922-1926). Le baron Rodolphe d'Erlanger (1949 et 1959) est le premier à proposer pour le système mélodique de la tradition vivante un outillage théorique et musicologique puisé dans la littérature médiévale. La question du caractère savant de la musique khédiviale est approfondie par Frédéric Lagrange (1994: 455-467).

8. Gilles Deleuze et Félix Guattari (1980, chapitre «La ritournelle»), posent la notion de territoire, " au sens non exclusivement spatial d'agencement de rapports de voisinage, de rapports différentiels définissant eux-mêmes des singularités au sein de multiplicités de type conceptuel aussi bien que physique» (During 1994: 130). Ils définissent la ritournelle de la manière suivante: «En un sens général, on appelle ritournelle tout ensemble de matières d'expression qui trace un territoire, et qui se développe en motifs territoriaux, en paysages territoriaux.» (Deleuze et Guattari 1980: 397).

9. «[Les modes toponymes et ethnonymes] se sont reterritorialisés dans l'espace idéel de la musique moyen-orientale, dans le plan des formes, des systèmes musicaux» (During 1994: 131).

10. «Dans les deux liturgies [judaïque et chrétienne initiale], la parole chantée a valeur mystique. Elle n'est pas un art en soi, elle n'est pas un ornement du culte, mais une sorte de pont entre l'homme et Dieu. En sorte que, dans le rituel juif, toute parole est plus ou moins cantillée pour recevoir, du son musical, cette ampleur sonore, cette solennité qui la porte jusqu'aux régions instinctives de l'être.» 
11. Les premières mentions écrites de cette forme remontent aux sources ottomanes du début du XVII (Feldman s.d.: 9).

12. Concept développé par les philosophes de l'antiquité grecque et du Moyen Age arabo-persan (les termes sont 'atar et al dans ce cas) et repris par les théoriciens de la musique ecclésiale byzantine, signifiant notamment: caractère éthique et esthétique véhiculé par un texte ou une phrase musicale, pouvant induire un état psychologique déterminé chez l'auditeur, voire un état spirituel (voir: Farmer 1926-1986, Reinach 1926, Abou Mrad 1989). La question du plaisir musical associé à la cantillation coranique est étudiée par Frédéric Lagrange (1996: 55).

13. Du recueil de muwaššạāt intitulé Safinat al-mulk et édité 1840, par Muhammad Šihāb a-d-Dīn, au recueil de muwaššăāt et de adwār édité par Mụammad Kāmel al-Khula'ī dans son ouvrage théorique Kitāb al-Mūsīqī a-š-šarqī (1904).

14. Tartill, dérivé du verbe rattala, supporte également les deux sens de tajwìd.

15. Tout en respectant sur le plan rythmique et phonétique les contraintes prosodiques susmentionnées, le récitant s'autorise à des répétitions de fragments de versets, sans répétition mélodique, selon les aléas de la respiration, et élabore un phrasé mélodique complexe et varié, à caractère formulaire improvisatif, dont l'ambitus dépasse parfois les deux octaves et qui module aisément, parfois d'une manière brusque et se conclut par des cadences ou qaflāt (sing. qafla) à l'emporte-pièce (Lagrange 1996: 52-57).

16. Pour «récitation», qirā'a est inféodée à Qur'ān ou Coran et admet le sens de lecture introvertie. On lui préférera tilāwa qui affirme l'extraversion de la lecture. Pour «chantée», il faut éviter tout usage de $\dot{g} i n \bar{a}$ ' (chant artistique), totalement entaché de profanité et associé à l'idée de composition à rythme cyclique, et d'inšăd qui se rapporte au chant (y inclus la cantillation, voir paragraphe suivant) de la poésie. En revanche, tarnim, qui provient du verbe rannama, souligne l'aspect mélodique du chant, notamment par son dérivé emphatique tarannum (pl. tarannumāt) qui provient du verbe tarannama (amplification de rannama) et signifie «modulation de la voix», c'est-à-dire "mélisme» (à caractère improvisatif) ou "vocalise» (Sỉbawayhī, cité par Shiloah 1972: 198), y compris, dans sa forme extrême, "mélismes sans paroles», autrement dit, sur onomatopées. Aussi l'auteur de ces lignes préconise-t-il de traduire cantillation par « tilāwa murannama».

17. Substantif dérivé du verbe anšada dont provient également inšād.

18. Le Traité anonyme dédié au Sultan Osmānlī Mụammad II (Erlanger 1939: 235-236) fait référence à 'Abd al-Qādir Al-Gaybī Al-Marāğ̄i (d. 1435) lorsqu'il décrit les différentes formes musicales. Un qawl, attribué à Șafiy A-d-Dīn Al-Urmawī (XIII ${ }^{e}$ siècle) et noté alphabétiquement au début du XIV siècle par les soins de Quṭb A-d-Dīn A-š-Šīrāzī, et transcrit en notation moderne par Owen Wright (1978: 282-291), comprend une séquence intercalaire médiane mélismatique à tropes onomatopéiques (Tî̀i larā dìr nāa...), qui répond au descriptif de șawt al-wasaț.

19. Christian Poché (ibid.: 58) rapporte que le zajal libanais est pratiqué surtout par les communautés chrétiennes qui ne craignent pas d'affirmer qu'il a été inventé par Saint Ephrem à Edesse au IV $\mathrm{IV}^{\mathrm{e}}$ siècle.

20. 1840-1892 Safinat al-mulk wa-nafisat al-fulk (Vaisseau royal et joyau du firmament), Le Caire. Voir également Moussali, s.d.

21. L'usage de ces cycles est restreint, cantonné à de rares muwaššăāt. De même, leur exécution est hétérodoxe, dans la mesure où le détail de certains cycles binaires longs n'est pas toujours respecté dans la battue et étant donné que la ligne musicale est torturée à force de contretemps et de syncopes (Lagrange 1996: 89). Il semble, en effet, que les artistes égyptiens aient trouvé aussi rébarbatif qu'inutile cet exercice de mémorisation scolaire d'une longue série de battues, lorsqu'il est possible de la monnayer par une série de cellules rythmiques binaires simples et identiques, telle la wahda à deux temps.

22. Le violon européen a remplacé au cours de la seconde moitié du XIX ${ }^{\mathrm{e}}$ siècle les rabāb et kamanja, vièles à pique traditionnelles locales et régionales. 
23. La littérature de l'époque ne décrit pas, pour ne pas dire ne mentionne pas, cette forme, vu le peu de cas donné à la musique instrumentale dans un contexte arabe traditionnel. Les enregistrements témoignent pourtant du très haut niveau artistique atteint dans cette forme qui appelle à une improvisation socialisée car elle fait dialoguer les solistes.

24. De rares spécimens ont été composés sur le cycle ternaire du samāì dārij ou sur le cycle asymétrique à neuf temps de l'aqșāq.

25. Le modèle en est le maestro égyptien 'Abd el-Ḥalīm Nwīrā, fondateur en 1967 des chœurs et orchestre « Firqat al-mūsīqā al-‘arabiyya» à l'Opéra du Caire (El-Shawan 1987: 155-156).

\section{RÉSUMÉS}

L'étude des formes musicales de la tradition musicale savante de l'Orient arabe passe avant tout par l'analyse des processus d'élaboration du phrasé. Cet article propose à cet égard une typologie axée sur l'opposition entre la cantillation improvisative plurimodulaire, au rythme non mesuré, qui prend racine dans le verbe (prose sacrée) et effectue une sorte de projection temporelle progressive de l'architecture modale, d'une part, et, d'autre part, la ritournelle précomposée répétitive monomodulaire, au rythme cyclique, qui prend racine dans le geste (profane). Du métissage entre ces deux prototypes surgissent des formes mixtes qui vont de la cantillation mesurée de la poésie et de la cantillation instrumentale (taqsìm) à l'hymne strophique, en passant par différentes sortes de responsorial. Des formes constituées selon ce schéma sont apparues en Egypte et au Levant au cours de la Nahda (Renaissance arabe) du XIX ${ }^{\mathrm{e}}$ siècle, et se sont intégrées à la performance de la waṣla qui est analysée ici en tant que parcours obligé en trois paliers assujettis tant à l'unicité modale du maqām, qu'à une dialectique ternaire opposant précomposé à caractère strophique à improvisé cantillatoire.

\section{AUTEUR}

\section{NIDAA ABOU MRAD}

Nidaa ABOU MRAD, violoniste, compositeur et docteur en musicologie, spécialiste de la tradition musicale savante du Proche-Orient arabe, est le directeur académique de l'Institut Supérieur de Musique de l'Université Antonine au Liban et le directeur du Centre des Traditions Musicales de l'Orient Arabe et de la Méditerranée, rattaché à cet Institut. A son actif musical : treize CD et sa participation à des festivals internationaux. A son actif musicologique: plusieurs articles scientifiques parus dans des encyclopédies et des revues spécialisées, et édition de deux ouvrages musicologiques collectifs. 